\title{
An approximate multiscale model for aging viscoelastic materials exhibiting time-dependent Poisson's ratio
}

\author{
F. Lavergne ${ }^{\mathrm{a}}$, K. Sab ${ }^{\mathrm{a}, *}$, J. Sanahuja $^{\mathrm{b}}$, M. Bornert ${ }^{\mathrm{a}}$, C. Toulemonde ${ }^{\mathrm{b}}$ \\ ${ }^{a}$ Université Paris-Est, Laboratoire Navier (ENPC, IFSTTAR, CNRS) \\ 77455 Marne-la-Vallée Cedex, France \\ ${ }^{b}$ Département Mécanique des Matériaux et des Composants, EDF R\&D, Site des Renardières, Avenue \\ des Renardières, 7r818 Moret-Sur-Loing Cedex, France
}

\begin{abstract}
A multi-scale homogenization scheme is proposed to estimate the time-dependent strains of fiber-reinforced concrete. This material is modeled as an aging linear viscoelastic composite material featuring ellipsoidal inclusions embedded in a viscoelastic cementitious matrix characterized by a time-dependent Poisson's ratio. To this end, the homogenization scheme proposed in 1 is adapted to the case of a time-dependent Poisson's ratio and it is successfully validated on a non-aging material computed in the Fourier domain. Finally, the new extended estimates of the time-dependent strains of fiber-reinforced concrete are compared to the experimental measurements of Chern and Young [2] and the effects of the volume fraction and aspect ratio of the steel fibers on the time-dependent strains of fiber-reinforced concrete are investigated.
\end{abstract}

Keywords:

aging, creep, homogenization, ellipsoid

\section{Introduction}

Fiber-reinforced concrete can be modeled as an aging linear viscoelastic materials: a uniform stress induces a proportional time-dependent strain. Moreover, it can be described as a matrix-inclusion composite material. Two scales are distinguished: the mesoscopic scale (Fig. 1b), where inclusions larger than $100 \mu \mathrm{m}$ are accounted for, and the microscopic scale of the cement paste (Fig. 1a). The basic creep of concrete stems from the microscopic scale [3] and homogenization methods have been applied to bridge the gap between the scales [4, 5, 6, 7,. Some aspects of fiber-reinforced concrete make it challenging.

The aspect ratio of steel fibers in fiber-reinforced concrete can be as large as $a / b=100$ 2]: full 3D numerical simulations 6, 8, 7] would hardly take account of such aspect ratios for the moment since the RVE would be too large and the details too small to be accurately depicted.

\footnotetext{
*Corresponding author. Tel: +33164153749

Email address: karam.sab@enpc.fr (K. Sab)

Postprint of Cement Concrete Research doi:10.1016/j.cemconres.2016.04.015
} 


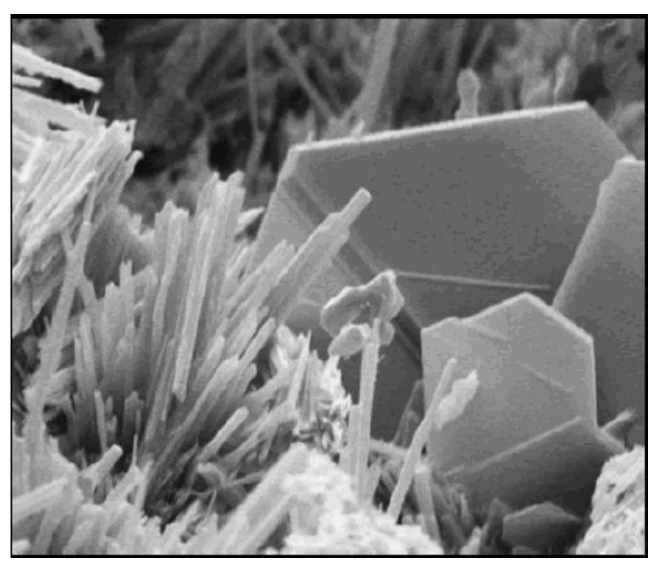

(a) A SEM image of a cement paste performed by Walker et. al. [56]. The image shows ettringite needles and also the plate-like morphology of portlandite.

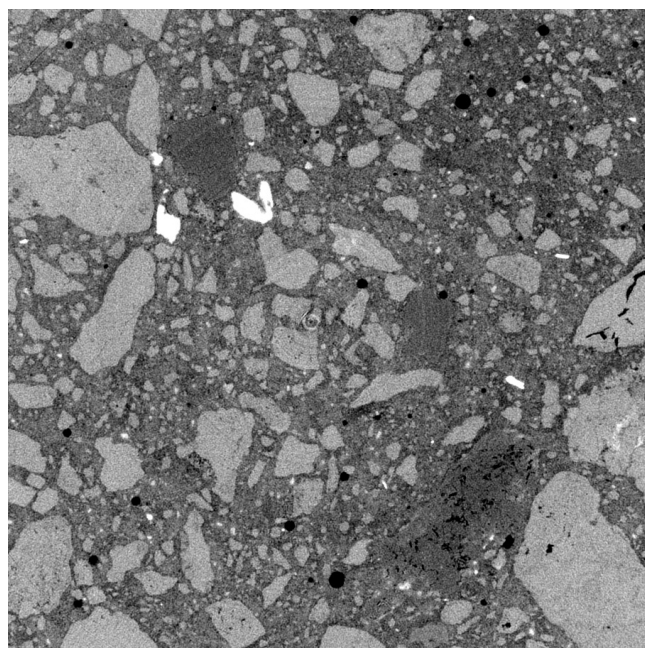

(b) A $5.7 \mathrm{~mm} \times 5.7 \mathrm{~mm}$ slice of a X-ray tomography of concrete performed at the Navier Laboratory. The aggregates and the trapped air can be distinguished from the cement paste.

Accounting for the aging viscoelastic properties of the matrix is still a challenge for homogenization schemes. The Mori-Tanaka 9, 10, scheme and the Ponte Castañeda-Willis scheme [11] have been designed to retrieve the elastic behavior of composites featuring ellipsoidal inclusions. These schemes are coupled to the correspondence principle [12, 13] to handle the case of non-aging viscoelastic materials [14, 15, [16. Nevertheless, modern iterative homogenization methods operate in the time domain [17, 18, 19, 20, to avoid inverting the Laplace-Carson transform.

Regarding aging viscoelastic materials, a closed-form solution has been proposed by Sanahuja 21] to handle the case of spherical inclusions embedded in an aging linear viscoelastic matrix. Moreover, a reliable and efficient numerical procedure has been proposed to estimate the overall viscoelastic behavior of the composite material: it does not require inverting the Laplace-Carson transform and is able to handle any compliance. Sanahuja's closed-form solution has recently been extended to the case of elongated or flat inclusions embedded in a matrix featuring a time-independent creep Poisson's ratio 1. This restriction entails the scope of the extended method. Indeed, it cannot be introduced as-is in a multi-scale homogenization procedure of fiber-reinforced concrete, since it is likely that the estimated viscoelastic behaviors of materials at the mesoscopic scale do not feature a time-independent Poisson's ratio[7]. Consequently, there is a need to extend the analytical homogenization solutions [21, 1] to the case of elongated or flat inclusions embedded in matrices featuring a time-dependent Poisson's ratio.

This paper contains two original contributions:

- In the first section, the extended Sanahuja's method for a matrix featuring a timeindependent Poisson's ratio is briefly recalled 21, 1] and an approximated viscoelastic Eshelby's tensor for a matrix featuring a time-dependent Poisson's ratio is proposed. This approximated viscoelastic Eshelby's tensor is combined to the 
Mori-Tanaka homogenization scheme to estimate the time-depend strains of an asphalt concrete at $0^{\circ} \mathrm{C}[22$. The estimate of the complex Young modulus is successfully compared to the corresponding estimate computed in the Fourier space, hence validating the proposed approximation of the viscoelastic Eshelby's tensor.

- In the second section, the proposed procedure is applied to a fiber-reinforced concrete. The estimates of the time-dependent strains are compared to the experimental data of Chern and Young 2]. Finally, the effects of the volume fraction and aspect ratio of the steel fibers on the time-dependent strains of fiber-reinforced concrete are estimated.

\section{Semi-analytical homogenization of aging viscoelastic materials}

\subsection{Aging viscoelasticity and time-independent Poisson's ratio}

\subsubsection{Aging viscoelasticity}

The stress tensor $\sigma(t)$ in a viscoelastic material depends on the history of strain tensor $\varepsilon(t)$. If the constitutive law is linear, the Boltzmann superposition principle states that the material properties are defined by a relaxation function (fourth order tensor), $\mathbf{C}\left(t, t^{\prime}\right)$, such that:

$$
\sigma(t)=\int_{-\infty}^{t} \mathbf{C}\left(t, t^{\prime}\right) d \varepsilon\left(t^{\prime}\right)
$$

where the integral is a Stieltjes integral. Similarly, the compliance function (fourth order tensor), $\mathbf{J}\left(t, t^{\prime}\right)$ is such that:

$$
\varepsilon(t)=\int_{-\infty}^{t} \mathbf{J}\left(t, t^{\prime}\right) d \sigma\left(t^{\prime}\right)
$$

If the elapsed time since loading is the only relevant parameter, the material is non-aging:

$$
\mathbf{J}\left(t, t^{\prime}\right)=\mathbf{\Phi}\left(t-t^{\prime}\right)
$$

However, the assumption of non aging is not made in the following derivations. If the viscoelastic behavior is isotropic, a spherical relaxation function $K\left(t, t^{\prime}\right)$ and a deviatoric relaxation function $G\left(t, t^{\prime}\right)$ are defined, such that:

$$
\begin{aligned}
p(t) & =\int_{-\infty}^{t} 3 K\left(t, t^{\prime}\right) d e\left(t^{\prime}\right) \\
\sigma^{d}(t) & =\int_{-\infty}^{t} 2 G\left(t, t^{\prime}\right) d \varepsilon^{d}\left(t^{\prime}\right)
\end{aligned}
$$

where $e(t)=\operatorname{tr}(\varepsilon(t)) / 3, p(t)=\operatorname{tr}(\sigma(t)) / 3$. The tensors $\sigma^{d}(t)$ and $\varepsilon^{d}(t)$ are respectively the deviatoric parts of $\sigma(t)$ and $\varepsilon(t)$ :

$$
\begin{aligned}
\sigma_{i j}^{d}(t) & =\sigma_{i j}(t)-p(t) \delta_{i j} \\
\varepsilon_{i j}^{d}(t) & =\varepsilon_{i j}(t)-e(t) \delta_{i j}
\end{aligned}
$$

where $\delta_{i j}$ is the Kronecker symbol. Similarly, the spherical part $k\left(t, t^{\prime}\right)$ and the deviatoric part $g\left(t, t^{\prime}\right)$ of the compliance are defined, such that:

$$
\begin{aligned}
e(t) & =\int_{-\infty}^{t} 3 k\left(t, t^{\prime}\right) d p\left(t^{\prime}\right) \\
\varepsilon^{d}(t) & =\int_{-\infty}^{t} 2 g\left(t, t^{\prime}\right) d \sigma^{d}\left(t^{\prime}\right)
\end{aligned}
$$


The aging viscoelastic constitutive phases of the composite materials considered in [1] are supposed to have a time-independent Poisson's ratio $\nu$, defined as:

$$
\nu=\frac{3 K\left(t, t^{\prime}\right)-2 G\left(t, t^{\prime}\right)}{2\left(3 K\left(t, t^{\prime}\right)+G\left(t, t^{\prime}\right)\right)}
$$

Hence, the relaxation tensors of these materials have the following property [23]:

$$
\mathbf{C}\left(t, t^{\prime}\right)=\mathbf{C}(0,0) f\left(t, t^{\prime}\right)
$$

where $\mathbf{C}(0,0)$ is the instantaneous elastic stiffness at $t=0$ and $f\left(t, t^{\prime}\right)$ is a scalar function such that $f(0,0)=1$.

\subsection{Existing framework for homogenization}

\subsubsection{Eshelby's solution for aging viscoelastic materials}

The results presented in [1] are briefly recalled in the following paragraphs. Let us consider here an elastic solid of stiffness $\mathbf{C}(0,0)$ that undergoes a uniform eigenstrain $\varepsilon^{*}$ in a bounded domain $V$ of characteristic function $\chi_{V}(x)$. Because of the linearity of the equations governing local strain and stress fields, the strain $\varepsilon(x)$ at any point $x$ in the body is a linear function of the eigenstrain $\varepsilon^{*}$ :

$$
\varepsilon(x)=\mathbf{S}(x): \varepsilon^{*}
$$

Let us consider now an aging viscoelastic solid of relaxation tensor $\mathbf{C}(0,0) f\left(t, t^{\prime}\right)$ that undergoes an history of eigenstrain $\varepsilon^{*}(t)$ in the bounded domain $V$. The strain field history $\varepsilon(t, x)=\mathbf{S}(x): \varepsilon^{*}(t)$ is the solution to the aging viscoelastic problem 1 . In particular, if the bounded domain $V$ is of ellipsoidal shape, Eshelby 24] showed that the tensor $\mathbf{S}(x)$ is uniform on the inclusion and Eshelby's tensor $\mathbf{S}$ is defined. Consequently, for all eigenstrain histories $\varepsilon^{*}(t)$, the uniform strain field in the ellipsoidal inclusion $\varepsilon(t)$ reads:

$$
\varepsilon(t)=\mathbf{S}: \varepsilon^{*}(t)
$$

\subsubsection{Definition of Volterra's tensorial operators and properties}

The tensorial Volterra operators described by Sanahuja 21] have interesting properties which ease further computations. Let $\mathbf{C}_{a}\left(t, t^{\prime}\right)$ and $\mathbf{C}_{b}\left(t, t^{\prime}\right)$ be two relaxation tensors (order 4) and $\varepsilon(t)$ be an history of the strain field (tensor of order 2). The tensorial Volterra operator of order 2 , noted as $\stackrel{\circ}{:}$ is the operator such that:

$$
\mathbf{C}_{a}: \varepsilon(t)=\int_{-\infty}^{t} \mathbf{C}_{a}\left(t, t^{\prime}\right): d \varepsilon\left(t^{\prime}\right)
$$

It must be noticed that:

$$
H\left(t-t^{\prime}\right) \mathbf{1}_{4}: \varepsilon=\varepsilon
$$

where $H\left(t-t^{\prime}\right)$ is Heaviside's function and $\mathbf{1}_{4}$ is the unit tensor of order 4 . The tensorial Volterra operator of order 4 is such that:

$$
\mathbf{C}_{a}: \mathbf{C}_{b}\left(t, t^{\prime}\right)=\int_{\tau=-\infty}^{t} \mathbf{C}_{a}(t, \tau): d_{\tau} \mathbf{C}_{b}\left(\tau, t^{\prime}\right)
$$


Some properties of these operators are listed in the current section. Their proofs, in [1], rely on the causality principle. Obviously, these operators are bilinear. Moreover, the right and left identity of the tensorial Volterra operator of order 4 is $H\left(t-t^{\prime}\right) \mathbf{1}_{4}$ :

$$
\begin{aligned}
& H\left(t-t^{\prime}\right) \mathbf{1}_{4}: \mathbf{C}_{a}=\mathbf{C}_{a} \\
& \mathbf{C}_{a}: H\left(t-t^{\prime}\right) \mathbf{1}_{4}=\mathbf{C}_{a}
\end{aligned}
$$

These operators can be associated:

$$
\left(\mathbf{C}_{a}: \mathbf{C}_{b}\right): \varepsilon=\mathbf{C}_{a}:\left(\mathbf{C}_{b}: \varepsilon\right)
$$

The tensorial Volterra operator of order 4 is associative:

$$
\mathbf{C}_{a}:\left(\mathbf{C}_{b}: \mathbf{C}_{c}\right)=\left(\mathbf{C}_{a}: \mathbf{C}_{b}\right): \mathbf{C}_{c}
$$

Nevertheless, the Volterra operator is not commutative. The inverse of the relaxation tensor $\mathbf{C}_{a}$ is the compliance tensor $\mathbf{C}_{a}^{-1}$ such that:

$$
\mathbf{C}_{a}^{-1}: \mathbf{C}_{a}=H\left(t-t^{\prime}\right) \mathbf{1}_{4}
$$

The left and right inverses are equal since the Volterra operator is associative.

These notations are applied to the viscoelastic Eshelby's solution. The strain history in the inclusion $\varepsilon$ reads:

$$
\varepsilon=\mathbf{S} H^{\circ} \varepsilon^{*}
$$

The stress history in the inclusion reads:

$$
\sigma=\mathbf{C}:\left(\varepsilon-\varepsilon^{*}\right)
$$

\subsection{The approximated viscoelastic Eshelby's tensor}

The exact solution to the aging viscoelastic Eshelby's problem has been derived in [1] for material having a relaxation tensor complying with the property (8). Noticing that the variations of the Poisson's ratio of a compliance $\mathbf{J}\left(t, t^{\prime}\right)$ are limited, the idea is to represent this compliance as a sum of a compliance featuring a time independent Poisson's ratio plus a small correction term. So the first step is to define a reference compliance $\mathbf{J}_{m}\left(t, t^{\prime}\right)$ with a time-independent Poisson's ratio.

The isotropic compliance tensor $\mathbf{J}\left(t, t^{\prime}\right)$ features a spherical part $k\left(t, t^{\prime}\right)$ and deviatoric part $g\left(t, t^{\prime}\right)$. Since the Poisson's ratio of the reference compliance $\mathbf{J}_{m}\left(t, t^{\prime}\right)$ is time-independent, its spherical part is $k_{m}\left(t, t^{\prime}\right)$ and its deviatoric part is $\alpha k_{m}\left(t, t^{\prime}\right)$ where $\alpha$ is a positive scalar. The scalar $\alpha$ and $k_{m}\left(t, t^{\prime}\right)$ are defined so as to minimize a difference between $\mathbf{J}\left(t, t^{\prime}\right)$ and $\mathbf{J}_{m}\left(t, t^{\prime}\right)$ :

$$
\left(\alpha, k_{m}\left(t, t^{\prime}\right)\right)=\underset{\left(\beta, k_{r}\left(t, t^{\prime}\right)\right)}{\arg \min } \int_{t} \int_{t^{\prime}}\left(k\left(t, t^{\prime}\right)-k_{r}\left(t, t^{\prime}\right)\right)^{2}+A\left(g\left(t, t^{\prime}\right)-\beta k_{r}\left(t, t^{\prime}\right)\right)^{2} d t^{\prime} d t
$$

where the scalar $A>0$ represents the relative weight of the spherical and deviatoric parts of the compliance. $A$ is set to 1 . This definition of the distance between $\mathbf{J}\left(t, t^{\prime}\right)$ and $\mathbf{J}_{m}\left(t, t^{\prime}\right)$ ensures that $\mathbf{J}\left(t, t^{\prime}\right)$ and $\mathbf{J}_{m}\left(t, t^{\prime}\right)$ are identical if and only if $\mathbf{J}\left(t, t^{\prime}\right)$ features a 
time-independent Poisson's ratio. Indeed, the application which associates the reference compliance $\mathbf{J}_{m}\left(t, t^{\prime}\right)$ to the compliance $\mathbf{J}\left(t, t^{\prime}\right)$ is idempotent.

By differentiating the expression with respect to $k_{r}\left(t, t^{\prime}\right)$, the minimum $\left(\alpha, k_{m}\left(t, t^{\prime}\right)\right)$ must satisfy the following equation:

$$
k_{m}\left(t, t^{\prime}\right)-k\left(t, t^{\prime}\right)-\alpha g\left(t, t^{\prime}\right)+\alpha^{2} k_{m}\left(t, t^{\prime}\right)=0
$$

Hence, $k_{m}\left(t, t^{\prime}\right)$ is computed according to the following equation:

$$
k_{m}\left(t, t^{\prime}\right)=\frac{k\left(t, t^{\prime}\right)+\alpha g\left(t, t^{\prime}\right)}{1+\alpha^{2}}
$$

These two equations are combined and the result is differentiated with respect to $\alpha$ :

$$
\left(\alpha^{2}-1\right) \int_{t} \int_{t^{\prime}} k\left(t, t^{\prime}\right) g\left(t, t^{\prime}\right) d t^{\prime} d t+\alpha \int_{t} \int_{t^{\prime}}\left(k\left(t, t^{\prime}\right)\right)^{2}-\left(g\left(t, t^{\prime}\right)\right)^{2} d t^{\prime} d t=0
$$

The scalar $\alpha$ is a root of the quadratic polynomial presented in the previous equation. Consequently, $\alpha$ is:

$$
\alpha=\frac{-\int_{t, t^{\prime}}\left(k\left(t, t^{\prime}\right)\right)^{2}-\left(g\left(t, t^{\prime}\right)\right)^{2} d t^{\prime} d t+\sqrt{\Delta}}{2 \int_{t, t^{\prime}} g\left(t, t^{\prime}\right) k\left(t, t^{\prime}\right) d t^{\prime} d t}
$$

In the equation above, $\Delta$ reads:

$$
\Delta=\left[\int_{t, t^{\prime}}\left(k\left(t, t^{\prime}\right)\right)^{2}-\left(g\left(t, t^{\prime}\right)\right)^{2} d t^{\prime} d t\right]^{2}+4\left[\int_{t, t^{\prime}} k\left(t, t^{\prime}\right) g\left(t, t^{\prime}\right) d t^{\prime} d t\right]^{2}
$$

The scalar $\alpha$ is related to the Poisson's ratio of the reference material:

$$
\nu_{m}=\frac{\frac{1}{3}-\frac{1}{2 \alpha}}{\frac{2}{3}+\frac{1}{2 \alpha}}
$$

It must be noticed that $\alpha$ is positive and $-1<\nu_{m}<0.5$. Hence, the compliance of the reference material $\mathbf{J}_{m}\left(t, t^{\prime}\right)$ satisfies the thermodynamic restrictions listed in [25].

From a practical point of view, time is discretized into steps $0<t_{0}<\ldots<t_{n}$ and integrals are approximated as sums. For instance:

$$
\int_{t} \int_{t^{\prime}} k\left(t, t^{\prime}\right) g\left(t, t^{\prime}\right) d t^{\prime} d t \approx \sum_{i=0}^{n} \sum_{j=0}^{i} k\left(t_{i}, t_{j}\right) g\left(t_{i}, t_{j}\right)
$$

Hence, the time-independent Poisson's ratio of $\mathbf{J}_{m}\left(t, t^{\prime}\right)$ depends on the compliance $\mathbf{J}\left(t, t^{\prime}\right)$ and considered time steps $0<t_{0}<\ldots<t_{n}$.

The second step is to define an approximated viscoelastic Eshelby's tensor for $\mathbf{J}\left(t, t^{\prime}\right)$ by using the reference compliance $\mathbf{J}_{m}\left(t, t^{\prime}\right)$. To this end, it is now assumed that the difference $\Delta \mathbf{J}\left(t, t^{\prime}\right)=\mathbf{J}\left(t, t^{\prime}\right)-\mathbf{J}_{m}\left(t, t^{\prime}\right)$ is small:

$$
\Delta \mathbf{J}\left(t, t^{\prime}\right)<<\mathbf{J}_{m}\left(t, t^{\prime}\right)
$$


The tensor $\varepsilon^{*}(t)$ being the history of the eigenstrain in the ellipsoid $\chi_{V}$, the Eshelby's solution for material $\mathbf{J}_{m}\left(t, t^{\prime}\right)$ is computed as $\varepsilon_{m}=\mathbf{S}_{m}(x)^{\circ} \varepsilon^{*}$ and the stress field history

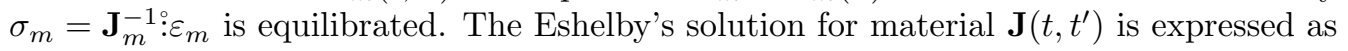
:

$$
\begin{aligned}
& \sigma=\sigma_{m}+\Delta \sigma \\
& \varepsilon=\varepsilon_{m}+\Delta \varepsilon
\end{aligned}
$$

where the correction to the stress field $\Delta \sigma<<\sigma_{m}$ and the correction to the strain field $\Delta \varepsilon<<\varepsilon_{m}$ are assumed to be small. Consequently, $\Delta \sigma$ is equilibrated at all times and $\Delta \varepsilon$ is compatible at all times. Moreover, the following equations stand:

$$
\begin{aligned}
\varepsilon-\varepsilon^{*} \chi_{V} & =\left(\mathbf{J}_{m}+\Delta \mathbf{J}\left(t, t^{\prime}\right)\right): \sigma \\
\varepsilon_{m}-\varepsilon^{*} \chi_{V} & =\mathbf{J}_{m}: \sigma_{m}
\end{aligned}
$$

The second equation is subtracted from the first and the term $\Delta \mathbf{J}: \Delta \sigma$ is neglected:

$$
\Delta \varepsilon=\mathbf{J}_{m}: \Delta \sigma+\Delta \mathbf{J}: \sigma_{m}
$$

Hence, $\Delta \varepsilon$ is Eshelby's solution for material $\mathbf{J}_{m}\left(t, t^{\prime}\right)$ and eigenstrain history $\Delta \varepsilon^{*}=$ $\left.\Delta \mathbf{J}\left(t, t^{\prime}\right)\right): \sigma_{m}$. This eigenstrain history is uniform on the ellipsoidal inclusion, it's value being:

$$
\Delta \varepsilon^{*}=\Delta \mathbf{J}: \mathbf{J}_{m}^{-1}:\left(\mathbf{S}_{m}-H \mathbf{1}_{4}\right) \stackrel{\bullet}{\varepsilon^{*}}
$$

where $\mathbf{S}_{m}$ is the viscoelastic Eshelby's tensor of material $\mathbf{J}_{m}\left(t, t^{\prime}\right)$. The eigenstrain history is assumed to be null out of the ellipsoid to solve Eshelby's problem:

$$
\Delta \varepsilon^{*}(t, x) \approx\left(\Delta \mathbf{J}: \mathbf{J}_{m}^{-1}:\left(\mathbf{S}_{m}-H \mathbf{1}_{4}\right) \stackrel{\bullet}{*}\right)(t) \chi_{V}(x)
$$

Finally, the approximated solution reads:

$$
\varepsilon=\left(\mathbf{S}_{m}(x)+\mathbf{S}_{m}(x) \stackrel{\bullet}{ } \mathbf{J}: \mathbf{J}_{m}^{-1}:\left(\mathbf{S}_{m}-H \mathbf{1}_{4}\right)\right) \stackrel{\bullet}{ } \varepsilon^{*}
$$

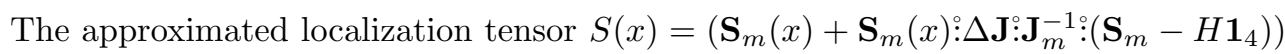
is uniform on the ellipsoid and an expression of the approximated viscoelastic Eshelby's tensor for the material $\mathbf{J}\left(t, t^{\prime}\right)$ reads:

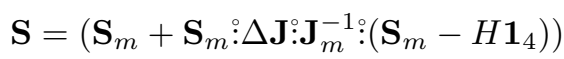

The equation above can be pictured as a linear approximation of the viscoelastic Eshelby's tensor on the space of compliances having $\mathbf{J}_{m}$ as reference compliance. Errors are triggered by assuming the eigenstrain history $\Delta \varepsilon^{*}$ to be null outside of the ellipsoid in equation (34) and by neglecting the term $\Delta \mathbf{J}: \Delta \sigma$ in equation $(32)$. The effect of these approximations on the estimated overall response of a composite material is investigated in section 1.4.2 on a non-aging material, where a reference solution can be computed in the Fourier domain.

\subsection{Applying the approximated scheme to non-aging asphalt concrete}

Eshelby's reasoning to extend Eshelby's solution to the inhomogeneity problem of an ellipsoidal inclusion having an elastic stiffness differing from the one of the remainder is applied to aging viscoelastic materials as in [1. Furthermore, the Mori-Tanaka scheme is adapted to produce estimates of the compliance of composite viscoelastic materials such as asphalt concrete. 


\subsubsection{Extension to the inhomogeneous inclusion}

Eshelby's reasoning to extend Eshelby's solution to the case of an inhomogeneous inclusion is still valid 1 . The expression of a localization tensor for the inhomogeneous inclusion $\varepsilon^{l}=\mathbf{T}^{\circ}: E$ has been derived. It is similar to the elastic case, expect for the use of the Volterra's operator:

$$
\mathbf{T}=\left[H \mathbf{1}_{4}+\mathbf{S}: \mathbf{C}^{-1}:\left(\mathbf{C}_{i}-\mathbf{C}\right)\right]^{-1}
$$

This result is restricted to an isotropic viscoelastic reference material $\mathbf{C}$. It must be noticed that there is no restriction on $\mathbf{C}_{i}$. For instance, the relaxation function $\mathbf{C}_{i}$ can correspond to an anisotropic aging viscoelastic material.

The Mori-Tanaka homogenization scheme. Mean field homogenization schemes considered in the present study are the Hashin-Shtrikman lower bound [26] or the Mori-Tanaka scheme 9, as reconsidered by Benveniste 10. These mean field methods rely on Eshelby's equivalent inclusion theory 24 to estimate the stress concentrations in ellipsoidal inclusions. The elastic Mori-Tanaka estimate $\mathbf{C}_{M T}^{e}$ accounts for the volume fraction of inclusions $c_{i}$ and the distribution of orientations of inclusions $f(\psi)$. It is the solution of equation:

$$
c_{i} \int_{\psi} f(\psi)\left(\mathbf{C}_{M T}^{e}-\mathbf{C}_{i}(\psi)\right): \mathbf{T}^{e}(\psi) d \psi+\left(1-c_{i}\right)\left(\mathbf{C}_{M T}^{e}-\mathbf{C}(0,0)\right)=0
$$

Here, $\mathbf{C}_{i}(\psi)$ is the elastic stiffness of inclusions having orientation $\psi ; \mathbf{C}(0,0)$ is the elastic stiffness of the matrix ; $\mathbf{T}^{e}(\psi)$ is the strain concentration tensor expressing the strain in the inclusions having orientation $\psi$ as a linear function of the strain at infinity, $\mathbf{C}(0,0)$ being the elastic stiffness tensor of the reference material. Tensors $\mathbf{C}_{i}(\psi)$ and $\mathbf{T}^{e}(\psi)$ are computed by rotating $\mathbf{C}_{i}(0)$ and $\mathbf{T}^{e}(0)$ using Bond transformations [27, 28.

The equation (38) is extended to the case of viscoelastic materials [21]:

$$
c_{i} \int_{\psi} f(\psi)\left(\mathbf{C}_{M T}-\mathbf{C}_{i}(\psi)\right): \mathbf{T}(\psi) d \psi+\left(1-c_{i}\right)\left(\mathbf{C}_{M T}-\mathbf{C}\right)=0
$$

where $\mathbf{T}(\psi)$ is derived by rotating $\mathbf{T}(0)$, which expression is given in equation (37). The relaxation tensor of the overall material $\mathbf{C}_{M T}$ is computed as:

$$
\mathbf{C}_{M T}=\left[c_{i} \int_{\psi} f(\psi) \mathbf{C}_{i}(\psi): \mathbf{T}(\psi) d \psi+\left(1-c_{i}\right) \mathbf{C}\right] \vdots\left[c_{i} \int_{\psi} f(\psi) \mathbf{T}(\psi) d \psi+\left(1-c_{i}\right) H \mathbf{1}_{4}\right]^{-1}
$$

Numerical computation. Following 21 and 29], time is discretized into steps $0<t_{0}<$ $\ldots<t_{n}$ and a quadrature rule is used to approximate integrals and solve the Volterra's equation. Hence, strain history and stress history are represented as vectors $\underline{\varepsilon}=\left[\varepsilon\left(t_{0}\right), \ldots, \varepsilon\left(t_{i}\right), \ldots, \varepsilon\left(t_{n}\right)\right]$ and $\underline{\sigma}=\left[\sigma\left(t_{0}\right), \ldots, \sigma\left(t_{i}\right), \ldots, \sigma\left(t_{n}\right)\right]$. The relaxation function $\mathbf{C}$ is represented as a matrix $\underline{\underline{C}}$ such that $\underline{\sigma}=\underline{\underline{C}} . \underline{\varepsilon}$. As written in references [21, 1], its generic blocks of size $6 \times 6$ reads: 


$$
2 \mathbf{C}_{i j}=\left\{\begin{array}{lr}
2 \mathbf{C}\left(t_{0}, t_{0}\right) & i=j=0 \\
\mathbf{C}\left(t_{i}, t_{0}\right)-\mathbf{C}\left(t_{i}, t_{1}\right) & i>0, j=0 \\
\mathbf{C}\left(t_{i}, t_{j-1}\right)-\mathbf{C}\left(t_{i}, t_{j+1}\right) & i>1,0<j<i \\
\mathbf{C}\left(t_{i}, t_{i-1}\right)+\mathbf{C}\left(t_{i}, t_{i}\right) & i>0, j=i \\
0 & i<j
\end{array}\right.
$$

This matrix is lower triangular per block, as could have been anticipated from the causality principle. An elastic behavior corresponds to a diagonal per block matrix. Computing $\mathbf{T}$ and $\mathbf{C}_{M T}$ resumes to matrix-matrix products, matrix-vector products and inverting a lower triangular per block matrices. It must be noticed that the last step is equivalent to time-stepping if blocked lines are inverted one after another 30 .

\subsubsection{Validation of the proposed method against a reference solution on asphalt concrete}

The asphalt concrete is a composite material made of elastic inclusions embedded in a bitumen and bitumen is a non-aging viscoelastic material. Consequently, the overall complex Young modulus of asphalt concrete may be estimated by analytical homogenization in the Fourier space. Moreover, it is a good candidate to validate the method described above since bitumen does not feature a time-independent Poisson's ratio.

The non-aging viscoelastic behavior of bitumen. The Poisson's ratio of asphalt concrete increases with temperature [22, 31, 32, and testing time [33, 32] and decreases with frequency $22,31,34,32$. The viscoelastic behavior of bitumen is commonly assumed to be purely deviatoric [35, 36, 37] to model asphalt concrete as a composite material by discrete elements 38, 39. This hypothesis is valid only at high temperature and low frequencies 22. The non-aging viscoelastic behavior of bitumen exhibits a change of Poisson's ratio with time elapsed since loading. It is well modeled by the 2S2P1D model [40, 41]. In this model, the complex Young Modulus $E^{*}(\omega)$ is a function of the pulsation $\omega:$

$$
E^{*}(\omega)=E_{\infty}+\frac{E_{0}-E_{\infty}}{1+\delta(j \omega \tau)^{-h}+(j \omega \tau)^{-k}+(j \omega \beta \tau)^{-1}}
$$

where $E_{0}, E_{\infty}, \delta, \tau, h, k$ and $\beta$ are scalar parameters adjusted on experimental results. Values presented in table 1 describe the master curve of a pure 50/70 penetration grade bitumen 22 at $0^{\circ} \mathrm{C}$. The bitumen of grade $50 / 70$ is normally used in the construction of pavements in France [42. A complex viscoelastic Poisson's ratio $\nu^{*}(\omega)$ is accounted for thanks to the following equation [22]:

$$
\nu^{*}(\omega)=\nu_{\infty}+\left(\nu_{0}-\nu_{\infty}\right) \frac{E^{*}(\omega)-E_{\infty}}{E_{0}-E_{\infty}}
$$

where $\nu_{\infty}=0.5$ and $\nu_{0}=0.36$ respectively corresponds to low frequencies and high frequencies. A series of non-aging Kelvin chains, named a DBN model 43 in the range of asphalt concrete, is adjusted to this compliance in the frequency domain, following the procedure of Di Benedetto et. al.[22]. The obtained values for parameters of the Kelvin chains are displayed in table 1 .

The change of the Poisson's ratio of bitumen from 0.38 to nearly 0.5 as the frequency is increased is a challenge for the approximated homogenization scheme proposed in the present article. Indeed, the value of 0.5 corresponds to incompressible materials : in 


\begin{tabular}{ccccccccc}
$\mathbf{E}_{\infty}(\mathrm{GPa})$ & $\mathbf{E}_{0}(\mathrm{GPa})$ & $k$ & $h$ & $\delta$ & $\beta$ & $\tau_{0}(\mathrm{~s})$ & $\nu_{\text {infty }}$ & $\nu_{0}$ \\
\hline 0 & 2.4 & 0.21 & 0.55 & 2.3 & 450 & 0.006 & 0.5 & 0.36
\end{tabular}

(a) 2S2P1D Model

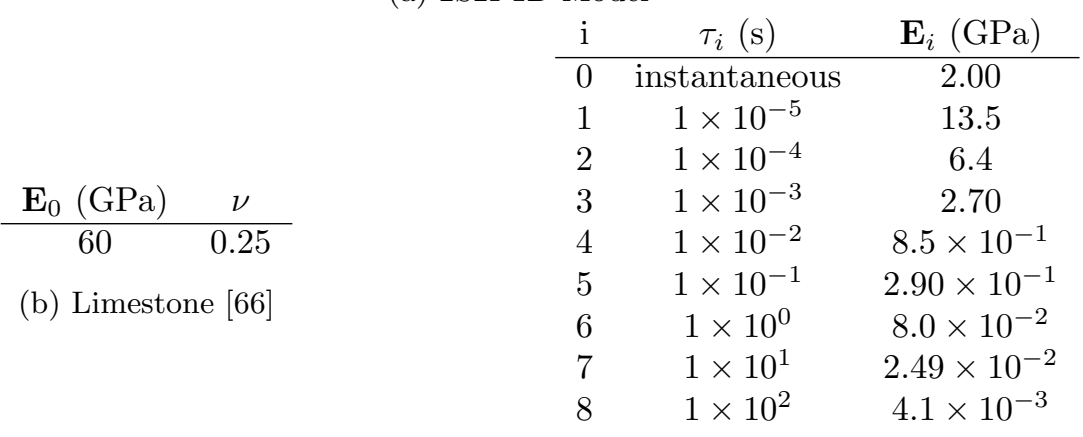

(c) DBN Model (Kelvin chains)

Table 1: Values describing the master curve of a pure 50/70 penetration grade bitumen 22] at $0^{\circ} \mathrm{C}$. The $\mathrm{DBN}$ model is adjusted in the range $[0.1 \mathrm{~Hz} ; 100000 \mathrm{~Hz}]$. The instantaneous Poisson's ratio is 0.38 . All Poisson's ratio of Kelvin chains are 0.5.

this range, a small change of the Poisson's ratio corresponds to a big change of the ratio $\alpha=\frac{3}{2} \frac{\nu_{m}+1}{1-2 \nu_{m}}$ between the deviatoric part and the spherical part of the reference compliance $\mathbf{J}_{m}\left(t, t^{\prime}\right)$.

The Mori-Tanaka scheme in the Fourier space. For a given pulsation $\omega$, the MoriTanaka estimate of the complex stiffness $\mathbf{C}_{M T}^{\omega}$ accounts for the volume fraction of inclusions $c_{i}$ and the distribution of orientations of inclusions $f(\psi)$. It is the solution of equation:

$$
c_{i} \int_{\psi} f(\psi)\left(\mathbf{C}_{M T}^{\omega}-\mathbf{C}_{i}(\psi)\right): \mathbf{T}^{\omega}(\psi) d \psi+\left(1-c_{i}\right)\left(\mathbf{C}_{M T}^{\omega}-\mathbf{C}_{m}^{\omega}\right)=0
$$

Here, $\mathbf{C}_{i}(\psi)$ is the elastic stiffness of inclusions having orientation $\psi ; \mathbf{C}_{m}^{\omega}$ is the elastic stiffness of the matrix corresponding to $\omega ; \mathbf{T}^{\omega}(\psi)$ is the strain concentration tensor expressing the strain in the inclusions having orientation $\psi$ as a linear function of the strain at infinity, $\mathbf{C}_{m}^{\omega}$ being the elastic stiffness tensor of the reference material. Tensors $\mathbf{C}_{i}(\psi)$ and $\mathbf{T}^{\omega}(\psi)$ are computed by rotating $\mathbf{C}_{i}(0)$ and $\mathbf{T}^{\omega}(0)$ using Bond transformations [27, 28. Formula to compute $\mathbf{T}^{p}(0)$ in the local reference are recalled in references [44, 45, 46.

Results on asphalt concrete. On the one hand, for a given frequency, the complex Young modulus and the Poisson's ratio of an asphalt featuring $32 \%$ of circular inclusions are estimated by the Mori-Tanaka scheme in the Fourier space. On the other hand, the proposed approximated homogenization scheme computes estimates of the time dependent strains in the time domain. Hence, a sinusoidal loading $\sigma_{x}(t)=\sin (\omega t)$ is applied and the magnitude and the phase of the complex Young modulus are identified on the corresponding time-dependent strains $\varepsilon_{x}(t) . \varepsilon_{x}(t)$ is identified as the sum of a periodic 

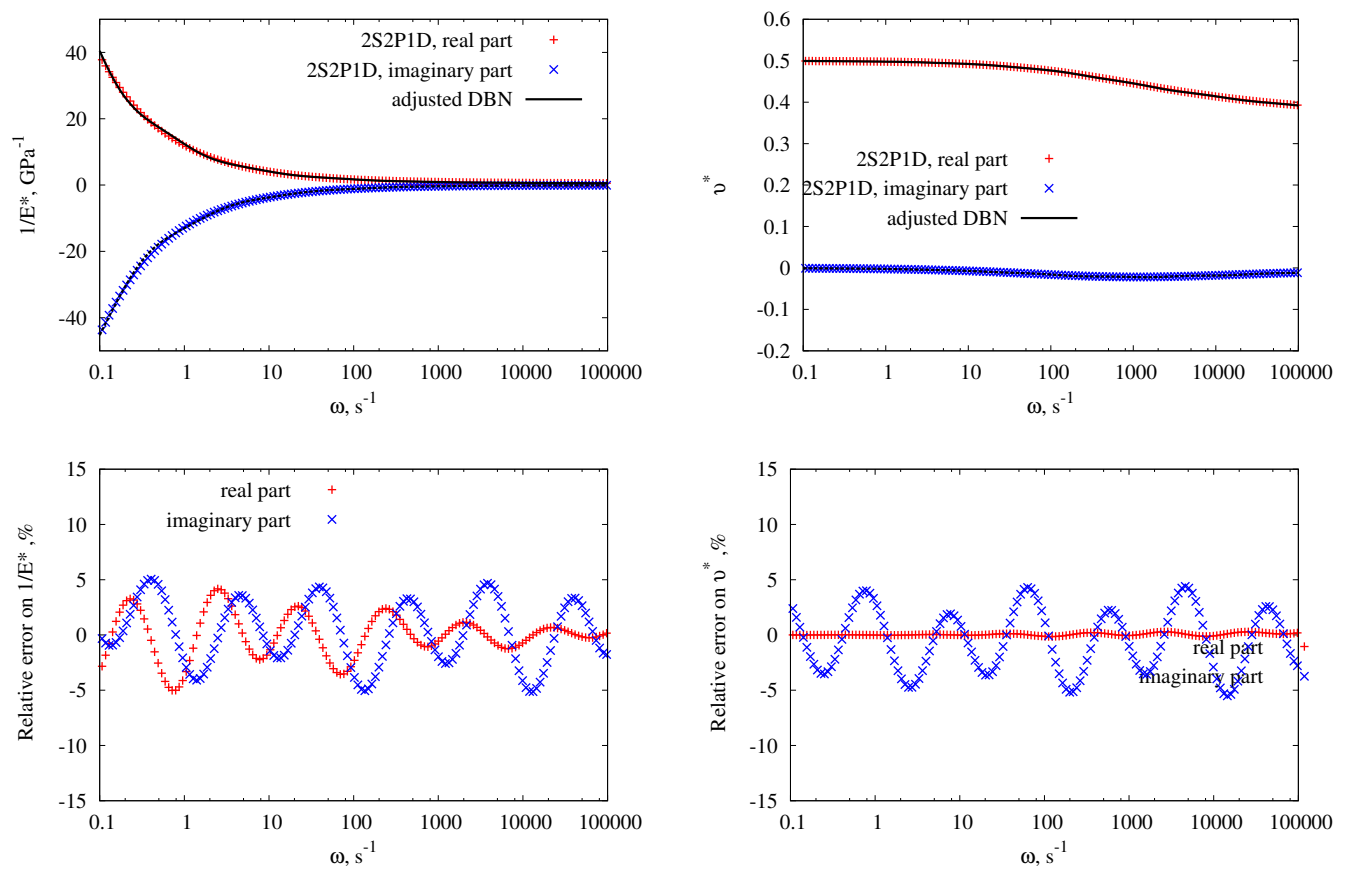

Figure 1: The DBN model is adjusted to the 2S2P1D model of a bitumen 22 in the range $[0.1 \mathrm{~Hz} ; 1000 \mathrm{~Hz}]$. The obtained real and imaginary parts of the complex Young Modulus (top left) and Poisson's ratio (top right) are displayed as functions of the pulsation $w$. The corresponding relative error are displayed below.

signal, a transient state and an offset.

$$
\varepsilon_{x}(t)=A \sin (\omega t+\phi)+\frac{B}{0.001+100 \omega^{2} t^{2}}+O
$$

where $|A|$ is related to the magnitude of $E(\omega)$ and $\phi$ to its phase. The scalars $B$ and $O$ corresponds respectively to the transient state and the offset.

The overall Young Modulus estimated by the proposed approximated homogenization scheme is close to the one obtained by using the Fourier method (Fig 2): both the magnitude and the phase coincide. Indeed, the relative difference between the estimates of the magnitude of the inverse of the complex Young modulus is lower than $2 \%$ for frequencies between $0.1 \mathrm{~Hz}$ and $100000 \mathrm{~Hz}$. Hence, the approximated viscoelastic Eshelby's tensor introduced to extend the analytical viscoelastic homogenization method to the case of a variable Poisson's ratio is validated. The proposed homogenization scheme is applied to an aging material in the next section. 

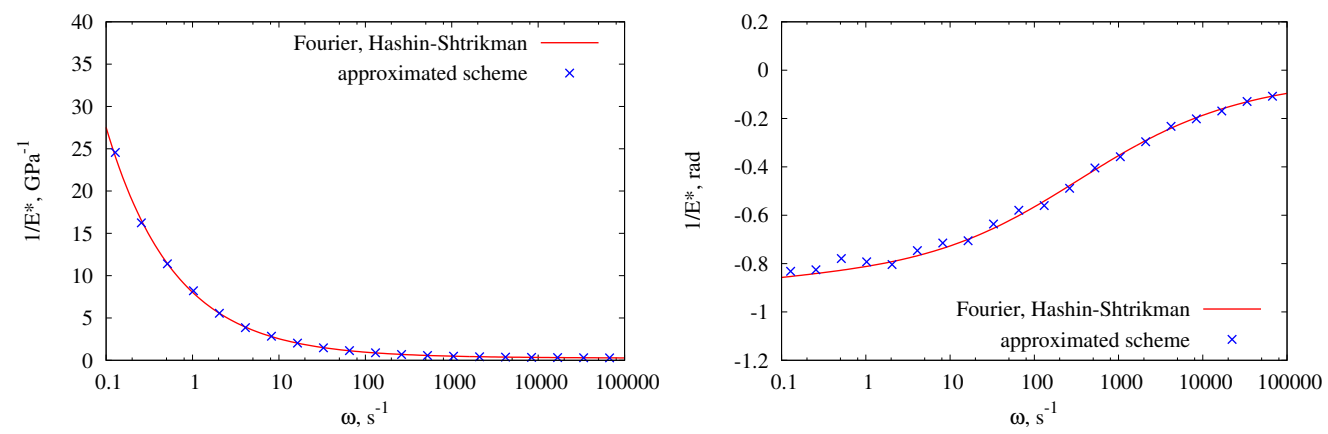

Figure 2: The magnitude (left) and phase (right) of the inverse of the complex Young modulus estimated by the Fourier method and the proposed homogenization scheme coincide at all frequencies. $\omega$.

\section{Applying the proposed scheme to fiber-reinforced concrete}

\subsection{Fiber reinforced concrete as a multi-scale material}

First, the behavior of the cement paste is estimated by the Mori-Tanaka scheme, the Calcium-Silicate-Hydrate (C-S-H) phase of the cement paste being the matrix. Then, the overall behavior of the fiber-reinforced concrete is estimated by the approximated Mori-Tanaka scheme, the cement paste being the matrix. Since the estimated relaxation tensor of the cement paste is produced by an homogenization scheme at the microscopic scale, its Poisson's ratio is time-dependent [Fig. 4 ] and the approximated homogenization scheme must be applied at the mesoscopic scale.

The fiber-reinforced concrete is to be described at each scale. In particular, the volume fraction of each phase and the corresponding behavior are presented.

\subsubsection{The mesoscopic scale}

At the mesoscopic scale, the Mori-Tanaka scheme is used, the cement paste being the reference material. Aggregates and steel fibers are considered as elastic for the present study, the cement paste being the sole responsible for the viscoelastic behavior of concrete. Their Young Moduli and Poisson's ratios are reported in table 2 Trapped air and entrained air are also accounted for in our homogenization method. Considered volume fractions of each phase are reported in table 2.

At the mesoscopic scale, the formulations of concrete may include aggregates [47, steel fibers [2], expanded polystyrene particles [48, 49] or wood shavings [50] as inclusions and such inclusions change the mechanical properties of the material. Indeed, experimental tests have shown that a volume fraction of $2 \%$ of steel fibers can reduce the basic creep of concrete 2.

\subsubsection{The microscopic scale}

The homogenization scheme of Mori-Tanaka is applied to upscale the viscoelastic behavior of the cement paste. This scheme has been used to estimate the time-dependent strain of a two-year old cement paste in the range of non-aging viscoelasticity [6]. Indeed, 


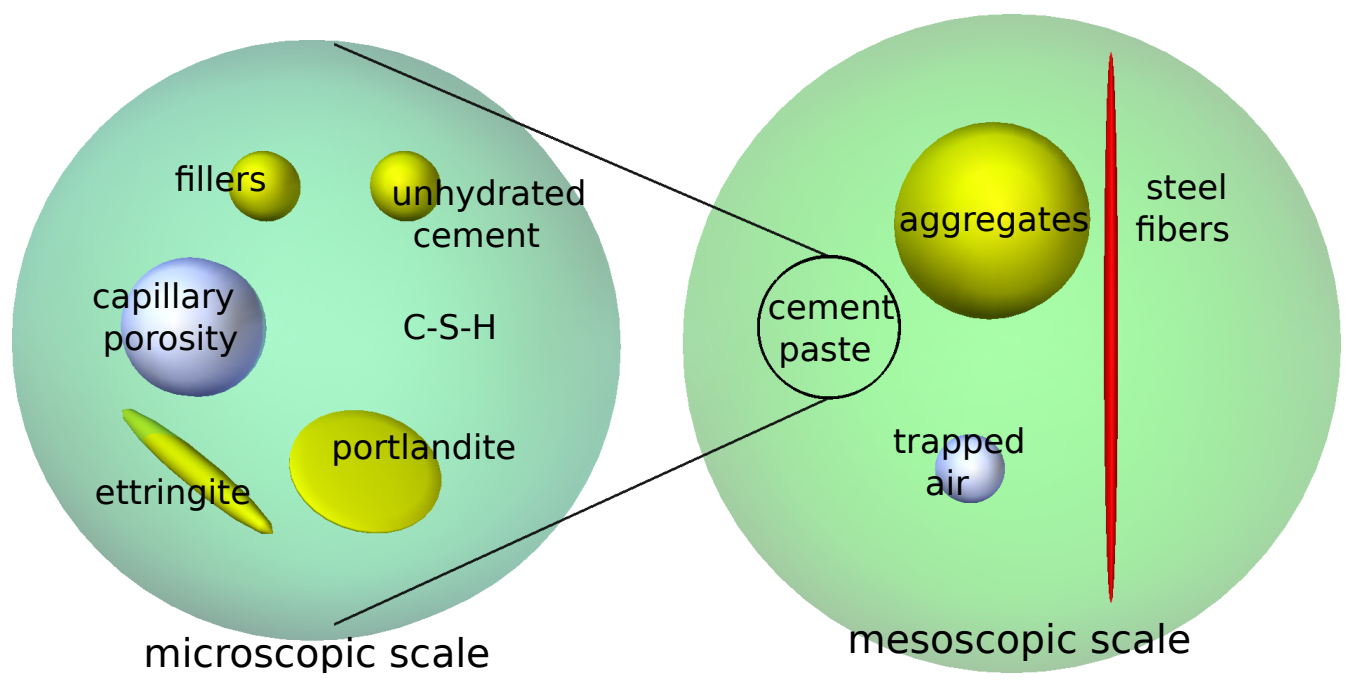

Figure 3: The overall behavior of the concrete is estimated by a two-step homogenization procedure. First, the behavior of the cement paste is estimated by the Mori-Tanaka scheme, the C-S-H being the reference material. Then, the behavior of the concrete is estimated by the Mori-Tanaka scheme, the cement paste being the reference material.

at the microscopic scale, the cement paste is a viscoelastic composite material. The fresh Portland cement paste consists in a mix of water and unhydrated cement particles. Hydration reactions produce various solid phases which represent the major part of an hydrated cement paste. Among them, the C-S-H phase percolates and constitutes the solid skeleton of the cement paste, thus increasing its stiffness. Other products of hydration of a cement paste include portlandite and ettringite. Since the volume of the products of the hydration is larger than the one of the solid reactants, the capillary porosity decreases with time.

It must be mentioned that this use of the Mori-Tanaka scheme was validated against $3 \mathrm{D}$ numerical simulations in the range of non-aging cementitious materials at the scale of the cement paste [6] and concrete [8. The novelty of the multi-scale homogenization method presented in the current section is that it is able to account for the aging of phases. Nevertheless, instead of modeling the hydration of the cement paste, it is assumed that the only effect of hydration is an increase of stiffness of C-S-H. Hence, the volume fraction of each phase is time-independent and set equal to the one estimated at 28 days by the hydration model of Jennings and Tennis [51, the one of Bernard et. al. [52] or the numerical hydration model CEMHYD3D [53, 54, 55].

All solid phases except C-S-H are considered as elastic isotropic [6] and their Young Moduli and Poisson's ratios are reported in table 2. SEM images of a cement paste show the needle-like ettringite and the plate-like portlandite [56, 1a the aspect ratios or ettringite and portlandite are respectively set to $a / b_{\text {ettringite }}=10$ and $a / b_{\text {portlandite }}=$ 0.1 .

The C-S-H features a viscoelastic behavior and the logarithmic creep properties of C-S-H measured by minutes-long nanoindentations are quantitatively representative of 


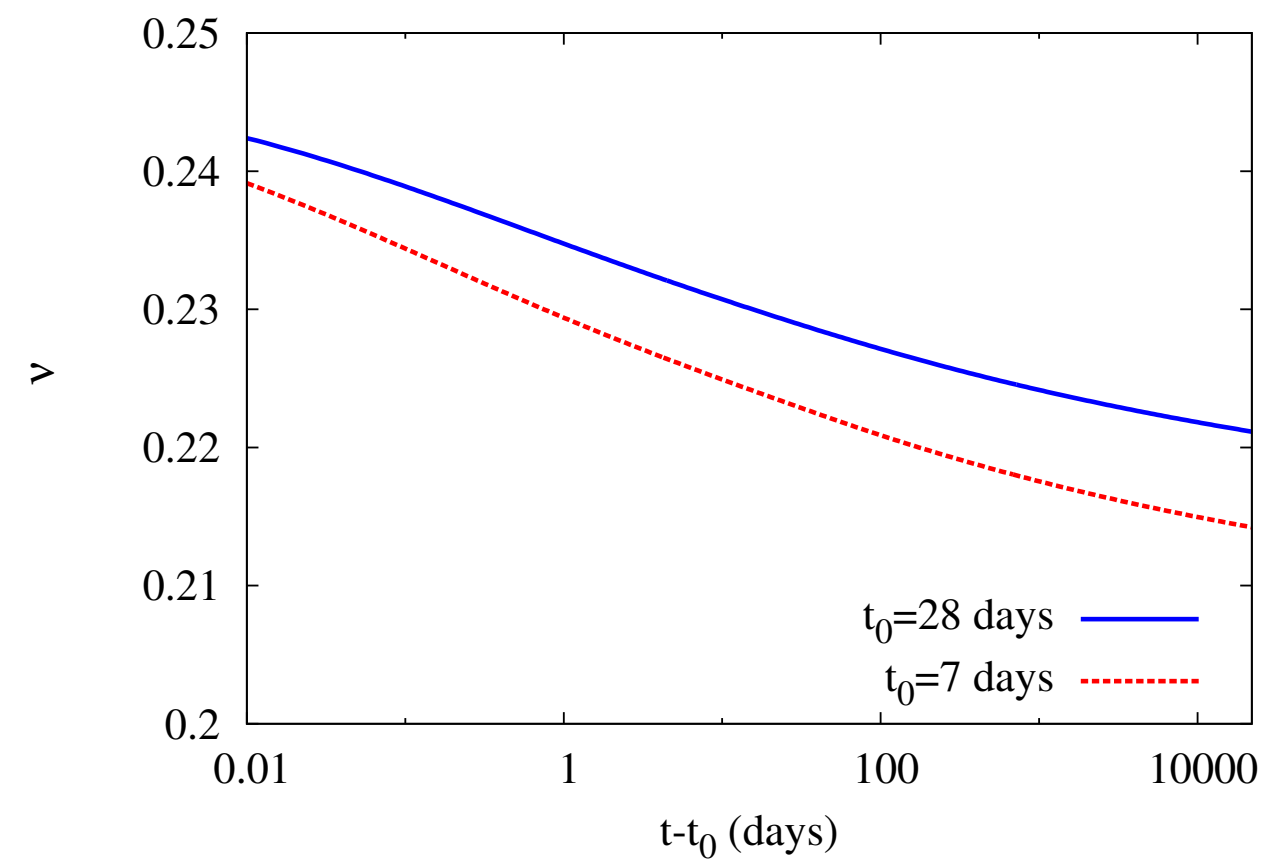

Figure 4: The viscoelastic Poisson's ratio $\nu$ of the cement paste is estimated: a bulk relaxation test and a shear relaxation test are performed based on the relaxation tensor estimated by the Mori-Tanaka scheme and equation (7) is applied. The viscoelastic Poisson's ratio $\nu$ changes with time of loading $t_{0}$ and time elapsed since loading $t$. Consequently, the approximated viscoelastic Eshelby's tensor is needed at the mesoscopic scale.

the long-term creep properties of macroscopic cementitious materials [3]. The C-S-H is modeled as an aging viscoelastic material and its compliance is described in the next section.

\subsubsection{The compliance of $C-S-H$}

The compliance of the C-S-H is the one of the B3 model, as described in [6, 1]. The B3 model [57, 58] has been designed to estimate the mechanical behavior of concrete, including its basic creep. The creep compliance of the B3 model $\mathbf{J}_{B 3}$ is the sum of two aging compliances. The first one $\mathbf{J}_{e a}$ represents the effect of hydration at early age and the second one $\mathbf{J}_{q 4}$ is irrecoverable, while satisfying the logarithmic long term trend of creep strains of concretes.

$$
\mathbf{J}_{B 3}\left(t, t^{\prime}\right)=\mathbf{J}_{e a}(t, t)+\mathbf{J}_{q 4}\left(t, t^{\prime}\right)
$$

The aging of a cement paste is treated as a consequence of volume growth of the loadbearing solidified matter (hydrated cement) whose compliance $\boldsymbol{\Phi}$ is non-aging:

$$
\mathbf{\Phi}\left(t-t^{\prime}\right) \propto \ln \left(1+\lambda_{0}^{-n}\left(t-t^{\prime}\right)^{n}\right)
$$


where $\lambda_{0}=1$ day. Although a value of $n=0.1$ is used at concrete scale [57, [58], higher values $(n=0,24)$ have been used for a cement paste with high water to cement ratio 59. At the nanometric scale of the calcium-silicate-hydrates (C-S-H), this parameter may be set at $n \approx 0.35[\underline{6}$.

The early-age compliance $\mathbf{J}_{e a}\left(t, t^{\prime}\right)$ of the solidifying cementitious material should satisfy the following conditions:

$$
\begin{aligned}
\frac{d \mathbf{J}_{e a}}{d t}\left(t, t^{\prime}\right) & =\frac{1}{v(t)} \frac{d \Phi}{d t}\left(t-t^{\prime}\right) \\
\mathbf{J}_{e a}(t, t) & =\mathbf{C}_{q 1}^{-1}+\frac{1}{v(t)} \mathbf{\Phi}(0)
\end{aligned}
$$

where $v(t)$ is proportional to the volume fraction of load-bearing material at time $t$ and $\mathbf{C}_{q 1}$ is the dynamic part of the elastic stiffness. The inverse of this dynamic Young Modulus is $q_{1}=0.6 / E_{28}$ where $E_{28}$ is the measured elastic stiffness at 28 days.

According to the $\mathrm{B} 3$ model, $v(t)$ reads:

$$
\frac{1}{v(t)}=q_{2}\left(\sqrt{\frac{\lambda_{0}}{t}}+0.29 *(w / c)^{4}\right)
$$

where $w / c$ is the water to cement weight ratio. $q_{2}$ is related to $q_{1}$ and the elastic stiffness at 28 days $E_{28}$. As performed in [6], the values of $E_{28}, q_{1}$ and $q_{4}$ are based on nanoindentation measurements of the elastic modulus of C-S-H [60, 61, 62]. These values are written in table 2

Following [1, the function $v(t)$ is modified under the assumption that aging stops once the Young modulus reaches 1.1 times the Young modulus at 28 days and $v(t)$ must remain below a maximum value $v_{\max }$, which reads:

$$
v_{\max }=\frac{1}{\frac{1}{1.1}-0.6} E_{28} \ln \left(1+0.01^{n}\right)
$$

A irrecoverable part of creep strain $\varepsilon_{q 4}$ in cementitious materials is taken account of in the second compliance $\mathbf{J}_{q 4}\left(t, t^{\prime}\right)$. This aging compliance features a logarithmic long term trend:

$$
\mathbf{J}_{q 4}\left(t, t^{\prime}\right)=\ln \left(\frac{t}{t^{\prime}}\right) \mathbf{C}_{q 4}^{-1}
$$

where the inverse of the Young modulus of $\mathbf{C}_{q 4}$ is $q_{4}=2.10^{-6} \mathrm{MPa}^{-1}$ for a saturated cement paste [6.

The proposed approximated homogenization scheme does not require the conversion of the compliance of the B3 model into a series of Kelvin chains. Such a conversion is useful to enable 3D numerical simulations relying on internal variables 6 , 8 , or to provide a microstructural interpretation of the compliance in which the characteristic times of the Kelvin chains can be related to the distribution of dimensions and the interface viscosity of viscous microscopic interfaces 63, 64, 65].

\subsection{Results on fiber-reinforced concrete}

The estimate of the time dependent strains produced by the approximated homogenization scheme are to be compared to the time-dependent strains measured by Chern and Young [2]. Then, the effects of the volume fraction and aspect ratio of the steel fibers on the time-dependent strains of fiber-reinforced concrete are estimated. 


\section{C-S-H}

Viscoelastic

nanoindentation Young modulus

$E_{2.6 s}$

$25 \mathrm{GPa}$

volume fraction

$47 \%$

parameters of model B3

$\begin{array}{cc}\nu & 0.24 \\ w / c & 0.5 \\ E_{28} & 16.4 \mathrm{GPa} \\ q_{1} & 0.0365 \mathrm{GPa}^{-1} \\ q_{2} & 0.646 \mathrm{GPa}^{-1} \\ q_{4} & 210^{-6} \mathrm{MPa}^{-1}\end{array}$

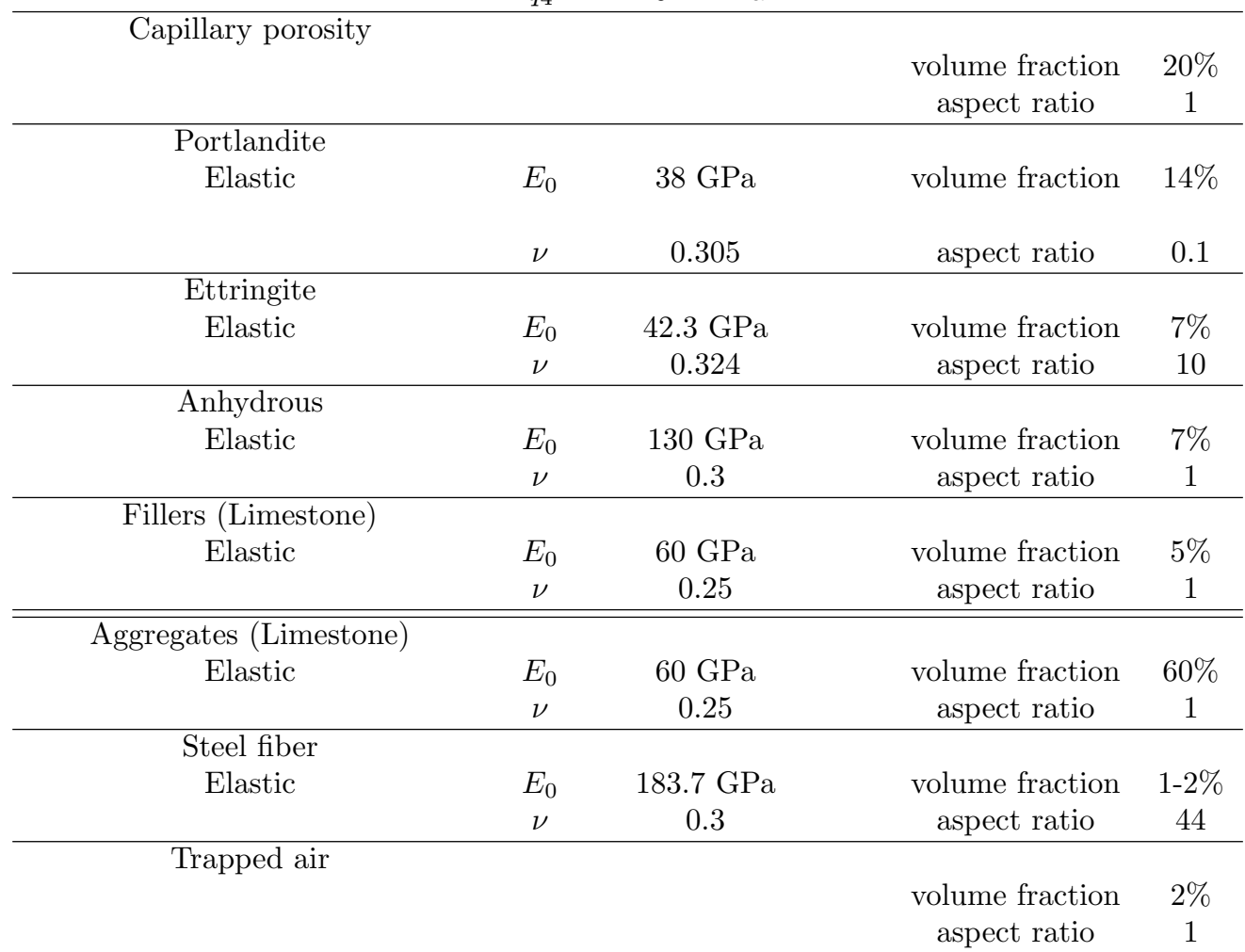

Table 2: Geometrical and mechanical parameters for the multi-scale homogenization of concrete. Parameters of the viscoelastic behavior of C-S-H are set according to the model B3. Elastic parameters are similar to those measure and used in previous homogenization studies of cementitious materials $85,86,66,87,60,52,88,61,55,89,60,62,6$. 


\begin{tabular}{c|cc|cc|cc|} 
fiber volume fraction & \multicolumn{2}{|c|}{$0 \%$} & \multicolumn{2}{c|}{$1 \%$} & \multicolumn{2}{c|}{$2 \%$} \\
time of loading $t_{0}$ & 7 days & 28 days & 7 days & 28 days & 7 days & 28 days \\
measured $E_{\text {exp }}\left(t_{0}+0.01\right.$ days, $\left.t_{0}\right)(\mathrm{GPa})$ & 19.3 & 23.5 & 22.2 & 25.7 & 22.3 & 26.1 \\
estimated $E\left(t_{0}+0.01\right.$ days, $\left.t_{0}\right)$ & 21.1 & 23.7 & 21.8 & 24.4 & 22.4 & 25.1 \\
measured $E_{\text {exp }}\left(t_{0}+170\right.$ days, $\left.t_{0}\right)(\mathrm{GPa})$ & 7.5 & 9.6 & 9.3 & 10.9 & 9.7 & 11.9 \\
estimated $E\left(t_{0}+170\right.$ days, $\left.t_{0}\right)$ & 10.2 & 12.8 & 10.9 & 13.5 & 11.5 & 14.1
\end{tabular}

Table 3: The experimental instantaneous Young Modulus and apparent Young Modulus 170 days after loading measured by Chern and Young 2] are compared to corresponding estimates produced by the multi-scale homogenization method. Values for different volume fractions of fibers and different time of loading are available.

\subsubsection{Comparison with experimental results}

Chern and Young 2] have performed creep tests on sealed samples of fiber-reinforced concrete, among other tests. Their study was focused on the influence of the volume fraction of steel fibers and time of loading on the time-dependent strains. The volume fraction of steel fibers was $c_{f}=0 \%, 1 \%$ and $2 \%$, their aspect ratio was $a / b=44$ and the times of loading were $t_{0}=7$ and 28 days. Since the water to cement ratio was 0.5 and little is known about the cement paste, the volume fraction at the scale of the cement paste are kept unchanged, as in table 2. The volume fraction of aggregates is arbitrarily set to $60 \%$ : even if the aggregate to cement weight ratio is known, the density of the aggregates are not provided. It is to be noticed that the Young modulus at 28 days of the concrete without fiber is $23.5 \mathrm{GPa}$, that is much lower that the Young Moduli of concrete with comparable $w / c$ measured by Granger (31.9 to $38.6 \mathrm{GPa}$ ) 66. This discrepancy is attributed to the quality of the aggregates and their Young modulus is set to $35 \mathrm{GPa}$. The time-dependent strains during a creep test are estimated, the instantaneous Young modulus $E\left(t_{0}+0.01\right.$ days, $\left.t_{0}\right)$ and the apparent Young modulus 170 days after loading $E\left(t_{0}+170\right.$ days, $\left.t_{0}\right)$ are compared to the experimental results of Chern and Young 2 in table 3 and in figure 5 . There is a difference between the estimated moduli and the measured ones, especially at long term: the multi-scale homogenization procedure underestimates the time-dependent strains. This difference is partly attributed to the temperature of the experiments $\left(23^{\circ} \mathrm{C}\right)$ which is higher than the temperature used in the B3 model $\left(20^{\circ} \mathrm{C}\right)$. However, a perfect match was not expected given the number of approximations that have been performed. Moreover, the parameters of the B3 model have not been modified to reduce the difference between the estimated long term Young moduli and the measured ones. Nevertheless, it should be emphasized that the trends of the estimates follow the ones of the experimental measurements for both the volume fraction of steel fibers and the time of loading. Indeed, our results are consistent with the experimental observations of Chern and Young 2]: the effect of steel fibers on the long term strain is larger than the effect on the instantaneous strain and concrete specimens containing higher volume fraction of fibers yield less basic creep. Moreover, the estimates of strains and the measurements of Chern and Young 2] are ranked in the same order: in both cases, loading a plain concrete at 28 days was more efficient at reducing creep strains that loading at 7 days a fiber-reinforced concrete featuring a volume fraction of fibers of $c_{f}=1 \%$. 


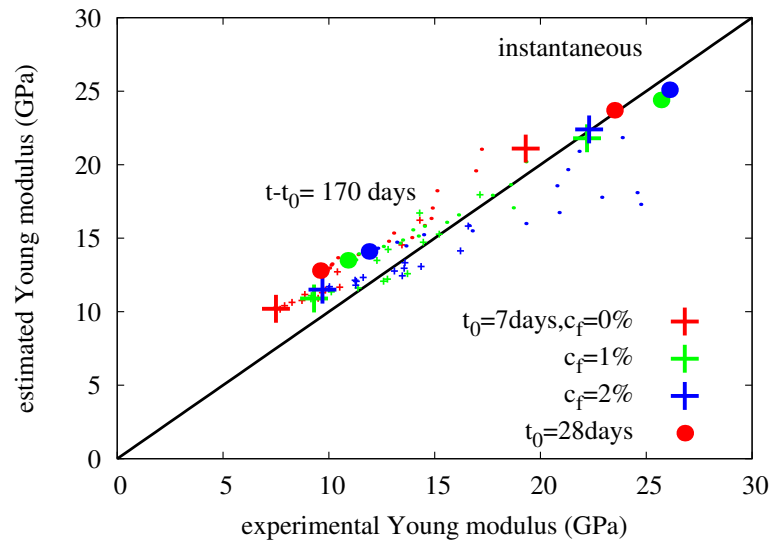

Figure 5: The instantaneous Young Modulus and apparent Young Modulus from 0 to 170 days after loading of fiber-reinforced concrete for different fiber volume fraction and time of loading of 7 days and 28 days. The experimental results of Chern and Young [2] are compared to the estimates of the multi-scale homogenization method.

\subsubsection{Influence of the steel fiber}

The aspect ratio of steel fibers being set to $a / b=44$, the estimate of the timedependent strain is computed for different volume fractions of steel fibers $c_{f}$. As shown in figure 6a, a volume fraction of $2 \%$ reduces the time-dependent strains. The steel fibers are expected to be more effective at reducing the long-term creep strains of the fiber-reinforced concrete. This expectation is consistent with the experimental results of Chern and Young[2].

The volume fraction of steel fibers being set to $c_{f}=2 \%$, the influence of the aspect ratio of fibers is studied and results are displayed on figure $6 \mathrm{~b}$. It is shown that the aspect ratio significantly affects the estimated time-dependent strains of the fiber reinforced concrete. Indeed, spherical steel inclusions are expected to be less efficient at reducing these strains than elongated fibers. The higher the aspect ratio is, the more efficient the steel fibers are. Yet, changing the aspect ratio of $a / b=44$ for $a / b=100$ makes little difference. It should be mentioned that the distribution of the orientations of the fibers is assumed to be isotropic. It is known that wall-effects due to the mold, casting and vibrating the concrete can affect the distribution of the orientations of the fibers 67, 68, 69.

\subsection{Discussions}

Regarding cementitious materials, it has been shown that a multi-scale homogenization of aging viscoelastic concrete is now feasible. Yet, existing multi-scale models in the range of elasticity or non-aging viscoelasticity included more scales. For instance, two different classes of C-S-H, featuring different densities and mechanical properties are accounted for in 61, 70, 4, 62, and a softer Interfacial Transition Zone is introduced between the aggregates and the cement paste at the scale of mortar or concrete in $71,72,73,74,75,76$. The main drawback of the homogenization method presented in the current article is that the volume fractions of each phase (unhydrated cement, 


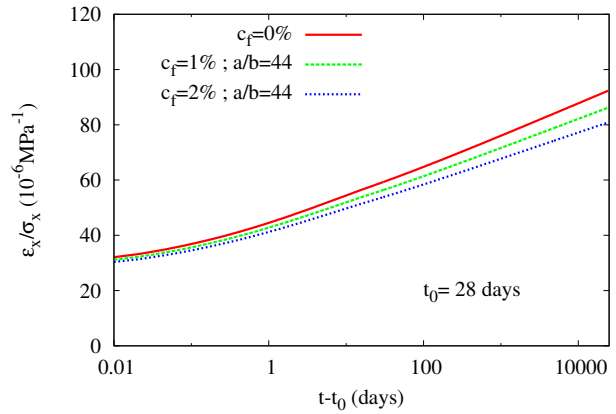

(a) Normalized uniaxial creep strains of fiberreinforced concrete estimated by the multiscale homogenization method are displayed as functions of the time elapsed since loading $t-t_{0}$ for different volume fractions of steel fibers. The aspect ratio $a / b$ of steel fibers is 44 .

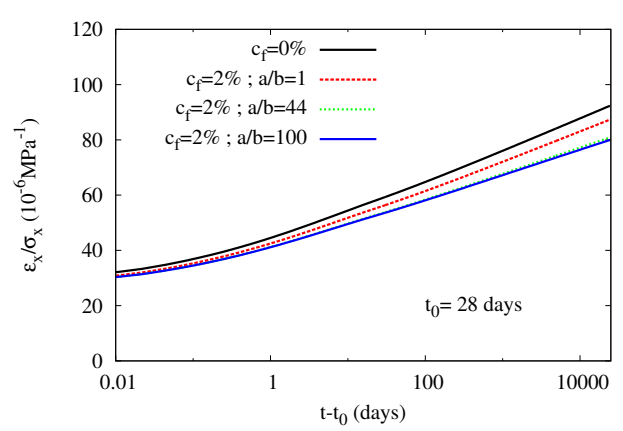

(b) Normalized uniaxial creep strains of fiberreinforced concrete estimated by the multiscale homogenization method are displayed as functions of the time elapsed since loading $t-t_{0}$ for different aspect ratios of steel fibers. The volume fraction of steel fibers is $c_{f}=2 \%$.

hydration products and porosity) are supposed to be time-independent while it is well known that these volume fractions change over time. Further research is necessary to account for changes of volume fractions related to the hydration of the cement paste, as performed in [77. Accounting for the progressive hydration of the cement paste would allow the investigation of creep at early age, that is before 7 days 78 . For instance, in [79], the influence of the composition of shotcrete on the load-level of tunnel shells has been successfully investigated using a micromechanics-based model where the aging is due to changes of the volume fractions of phases at the scale of the cement paste 5 .

The method exposed in the current article delivers an estimate of the complex Young Modulus of asphalt concrete which is similar to the analytical one in the Fourier space. Yet, from a practical point of view, the former is slower than the latter. Indeed, the computations in the Fourier space only consist in applying the Mori-Tanaka once for each frequency while the approximated scheme requires the introduction of time steps and an additional procedure to identify the complex Young Modulus of each frequency. The approximated scheme can become useful to handle complex loading histories at once or to upscale the mechanical properties of aging viscoelastic materials.

The usefulness of the approximated Eshelby tensor can be assessed by comparing the presented approximated estimates of the time-dependent strains to the one produced by assuming the Poisson's ratio of the matrix to be time-independent. For instance, in the latter, the compliance of the matrix is approximated as $\mathbf{J}_{m}$.

On the one hand, in the case of asphalt concrete, the overall time-dependent strains estimated by the approximated scheme are similar to those obtained by using the correspondence principle as a bulk creep test is considered (Fig. 6). But the estimated time-dependent strains obtained by assuming the Poisson's ratio of bitumen to be timeindependent are one order of magnitude lower and these estimates are not consistent with those produced by using the correspondence principle. Thus, the fact that the Poisson's ratio of bitumen is time-dependent is not to be neglected. Indeed, as the Kelvin chains 


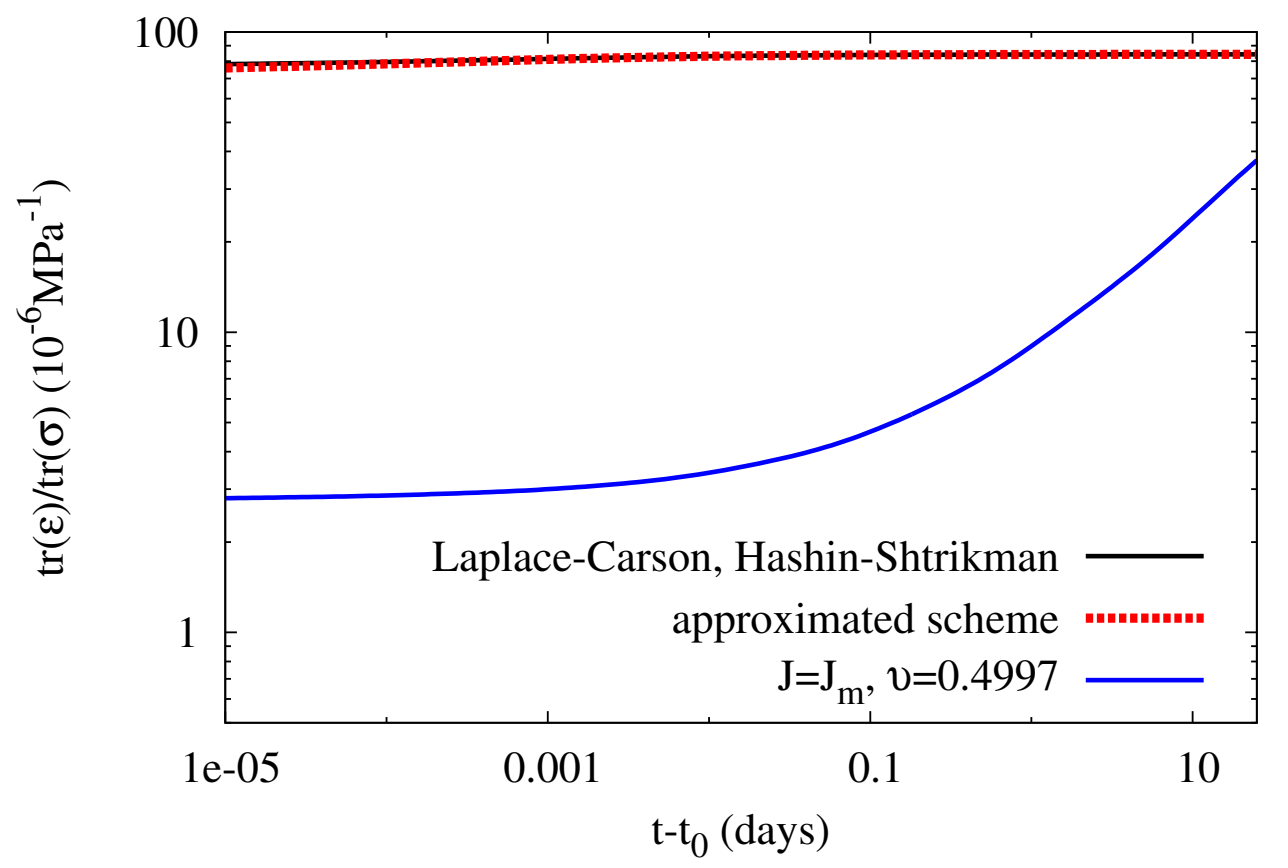

Figure 6: The overall time-dependent strains of an asphalt concrete are estimated by three different methods : the correspondence principle, the approximated scheme and the assumption of a time-independent Poisson's ratio. A bulk creep test is considered, the volume fraction of inclusions being $32 \%$.

are adjusted to the 2S2P1D model of bitumen [22], it must be noticed that the Poisson's ratio of each Kelvin chain was found to be close to 0.5. Consequently, the elastic bulk modulus is the only responsible for dilatational strains of bitumen and the asphalt concrete follows the same trend. Other materials share the same feature: the effect of the bulk viscosity is not considered as rubber 80, 81 is studied and the same assumption is made to model mixed oxides nuclear fuels [82, 83], except in the case of hot pressing [82.

On the other hand, the estimated Poisson's ratio of the cement paste remains in the range $[0.2 ; 0.3]$. Consequently, the approximated scheme and the assumption of a timeindependent Poisson's ratio $(\nu=0.212)$ lead to similar estimates of the time-dependent strains of a concrete featuring $60 \%$ of aggregates and $2 \%$ of voids: the relative differences between the overall estimated strains, computed using the approximated scheme as a reference, are lower than $2 \%$ in case of bulk creep test, shear creep test and uniaxial creep test. Moreover, the difference between the creep Poisson's ratio and the relaxation Poisson's ratio of the cement paste 84 can be investigated by the proposed approximated homogenization scheme. Results are consistent with the conclusions of Aili et. al. [84]: at the time of loading, both Poisson's ratios are equal to the elastic Poisson's ratio and the relative difference between the creep Poisson's ratio and the relaxation Poisson's ratio remains below $2 \%$ since the change of Poisson's ratio with time is moderate. Finally, 
the approximated scheme proposed in the present article proves more comprehensive and more reliable as it is able to handle both asphalt concrete and concrete.

\section{Conclusion}

The homogenization method of Sanahuja 21], which deals with spherical inclusions, was extended in [1] to ellipsoidal inclusions provided that the Poisson's ratio of the isotropic reference material is time-independent. In the current article, an approximated viscoelastic Eshelby's tensor is defined to handle any aging viscoelastic isotropic reference materials. Although the Mori-Takana scheme is the only homogenization scheme used in the present study, the same approximation can be performed for the Ponte Castañeda-Willis scheme [11. The approximated viscoelastic Eshelby's tensor is successfully validated against existing estimates on the time-dependent behavior of asphalt concrete, which is modeled as a non-aging viscoelastic material. Lastly, accounting for the time-dependent Poisson's ratio of bitumen in the homogenization of asphalt concrete is required but the Poisson's ratio of the hardened cement paste can be assumed to be uniform as concrete is considered.

Moreover, since both the behaviors of phases and the overall behavior of the homogenized material are represented as matrices, multi-scale homogenization of complex aging viscoelastic materials, such as fiber-reinforced concrete, is achieved. The influence of steel fibers volume fraction and aspect ratio on the aging viscoelastic behavior of the concrete is studied by estimating the time-dependent strains thanks to the multi-scale homogenization scheme defined above. The lessons extracted from these estimates are consistent with the experimentally-based conclusions of Chern and Young [2]: the time-dependent strain of a concrete are reduced by adding steel fibers or by loading the concrete as late as possible. Moreover, the influence of steel fibers on the long term creep strains is larger than the one on the elastic strain.

Nevertheless, the multi-scale method presented in this article is limited: as-is, it is not able to account for changes of the volume fractions of phases during the hydration of the cement paste. Hence, the modeling of aging is rather crude and could be improved if the homogenization method of Sanahuja were extended to the case of variable volume fractions.

[1] F. Lavergne, K. Sab, J. Sanahuja, M. Bornert, C. Toulemonde, Homogenization schemes for aging linear viscoelastic matrix-inclusion composite materials with elongated inclusions International Journal of Solids and Structures 80 (2016) 545 - 560. doi:http://dx.doi.org/10.1016/ j.ijsolstr.2015.10.014

URL http://www.sciencedirect.com/science/article/pii/S0020768315004308

[2] J.-C. Chern, C.-H. Young, Compressive creep and shrinkage of steel fibre reinforced concrete, International Journal of Cement Composites and Lightweight Concrete 11 (4) (1989) $205-214$ doi:http://dx.doi.org/10.1016/0262-5075(89) 90100-0

URL http://www.sciencedirect.com/science/article/pii/0262507589901000

[3] M. Vandamme, F.-J. Ulm, Nanoindentation investigation of creep properties of calcium silicate hydrates Cement and Concrete Research 52 (0) (2013) 38 - 52. doi:http://dx.doi.org/10.1016/ j.cemconres.2013.05.006

URL http://www.sciencedirect.com/science/article/pii/S0008884613001191

[4] J. Sanahuja, L. Dormieux, Y. Le Pape, C. Toulemonde, Modélisation micro-macro du fluage propre du béton in: 19ème Congrès Français de Mécanique, 2009, pp. 1-6.

URL http://documents .irevues . inist.fr/bitstream/handle/2042/36881/868.pdf?sequence=1

[5] S. Scheiner, C. Hellmich, Continuum microviscoelasticity model for aging basic creep of early-age concrete Journal of Engineering Mechanics 135 (4) (2009) 307-323. arXiv:http://dx.doi.org/ 
10.1061/(ASCE) 0733-9399(2009) 135:4(307) doi:10.1061/(ASCE) 0733-9399(2009) 135:4(307)

URL http://dx.doi.org/10.1061/(ASCE) 0733-9399(2009) 135:4(307)

[6] V. Šmilauer, Z. P. Bažant, Identification of viscoelastic C-S-H behavior in mature cement paste by FFT-based homogenization method Cement and Concrete Research 40 (2) (2010) 197 - 207. doi:10.1016/j.cemconres.2009.10.003

URL http://www.sciencedirect.com/science/article/pii/S0008884609002865

[7] X. Li, Z. Grasley, J. Bullard, E. Garboczi, Computing the time evolution of the apparent viscoelastic/viscoplastic Poisson's ratio of hydrating cement paste Cement and Concrete Composites 56 (0) (2015) 121 - 133. doi:http://dx.doi.org/10.1016/j.cemconcomp.2014.11.004 URL http://www.sciencedirect.com/science/article/pii/S0958946514002078

[8] F. Lavergne, K. Sab, J. Sanahuja, M. Bornert, C. Toulemonde, Investigation of the effect of aggregates' morphology on concrete creep properties by numerical simulations, Cement and Concrete Research 71 (0) (2015) 14 - 28. doi:http://dx.doi.org/10.1016/j.cemconres.2015.01.003 URL http://www.sciencedirect.com/science/article/pii/S0008884615000101

[9] T. Mori, K. Tanaka, Average stress in matrix and average elastic energy of materials with misfitting inclusions, Acta Metallurgica 21 (5) (1973) 571 - 574. doi:10.1016/0001-6160(73) 90064-3.

URL http://www.sciencedirect.com/science/article/pii/0001616073900643

[10] Y. Benveniste, A new approach to the application of Mori-Tanaka's theory in composite materials Mechanics of Materials 6 (2) (1987) 147 - 157. doi:http://dx.doi.org/10.1016/0167-6636(87) 90005-6

URL http://www.sciencedirect.com/science/article/pii/0167663687900056

[11] P. Ponte Castañeda, J. Willis, The effect of spatial distribution on the effective behavior of composite materials and cracked media Journal of the Mechanics and Physics of Solids 43 (12) (1995) $1919-$ 1951. doi:http://dx.doi.org/10.1016/0022-5096(95)00058-Q

URL http://www.sciencedirect.com/science/article/pii/002250969500058Q

[12] E. Lee, Stress analysis for linear viscoelastic materials, Rheologica Acta 1 (4-6) (1961) 426-430. doi:10.1007/BF01989085 URL http://dx.doi.org/10.1007/BF01989085

[13] J. Mandel, Cours de mécanique des milieux continus, Gauthier-Villars, 1966.

[14] Y. Wang, G. Weng, Influence of inclusion shape on the overall viscoelastic behavior of composites Journal of Applied Mechanics, Transactions ASME 59 (3) (1992) 510-518, cited By 69.

URL http://www.scopus.com/inward/record.url?eid=2-s2.0-0026914542\&partnerID=40\&md5= 4c4ba60fe65a5b05ac707ec637855ff0

[15] L. Brinson, W. Lin, Comparison of micromechanics methods for effective properties of multiphase viscoelastic composites, Composite Structures 41 (3-4) (1998) 353-367. doi:http://dx.doi.org/ 10.1016/S0263-8223(98)00019-1.

URL http://www.sciencedirect.com/science/article/pii/S0263822398000191

[16] M. Lévesque, M. Gilchrist, N. Bouleau, K. Derrien, D. Baptiste, Numerical inversion of the Laplace-Carson transform applied to homogenization of randomly reinforced linear viscoelastic media Computational Mechanics 40 (4) (2007) 771-789. doi:10.1007/s00466-006-0138-6 URL http://dx.doi.org/10.1007/s00466-006-0138-6

[17] N. Lahellec, P. Suquet, Effective behavior of linear viscoelastic composites: A time-integration approach, International Journal of Solids and Structures 44 (2) (2007) $507-529$. doi:http://dx. doi.org/10.1016/j.ijsolstr.2006.04.038

URL http://www.sciencedirect.com/science/article/pii/S002076830600148X

[18] A. Tran, J. Yvonnet, Q.-C. He, C. Toulemonde, J. Sanahuja, A simple computational homogenization method for structures made of linear heterogeneous viscoelastic materials Computer Methods in Applied Mechanics and Engineering 200 (45-46) (2011) 2956 - 2970. doi:http: //dx.doi.org/10.1016/j.cma.2011.06.012

URL http://www.sciencedirect.com/science/article/pii/S0045782511002301

[19] R. Masson, R. Brenner, O. Castelnau, Incremental homogenization approach for ageing viscoelastic polycrystals Comptes Rendus Mécanique 340 (4-5) (2012) 378 - 386, recent Advances in Micromechanics of Materials. doi:http://dx.doi.org/10.1016/j.crme.2012.02.021.

URL http://www.sciencedirect.com/science/article/pii/S1631072112000587

[20] S. Berbenni, F. Dinzart, H. Sabar, A new internal variables homogenization scheme for linear viscoelastic materials based on an exact Eshelby interaction law Mechanics of Materials 81 (0) (2015) 110 - 124. doi:http://dx.doi.org/10.1016/j.mechmat.2014.11.003 URL http://www.sciencedirect.com/science/article/pii/S0167663614001975

[21] J. Sanahuja, Effective behaviour of ageing linear viscoelastic composites: Homogenization approach 
International Journal of Solids and Structures 50 (19) (2013) 2846 - 2856. doi:http://dx.doi. org/10.1016/j.ijsolstr.2013.04.023

URL http://www.sciencedirect.com/science/article/pii/S0020768313001807

[22] H. Di Benedetto, B. Delaporte, C. Sauzéat, Three-dimensional linear behavior of bituminous materials: Experiments and modeling International Journal of Geomechanics 7 (2) (2007) 149157. arXiv:http://dx.doi.org/10.1061/(ASCE) 1532-3641(2007) 7:2(149) doi:10.1061/(ASCE) 1532-3641(2007) $7: 2(149)$

URL http://dx.doi.org/10.1061/(ASCE) 1532-3641(2007) 7:2(149)

[23] H. H. Hilton, S. Yi, The significance of (an)isotropic viscoelastic Poisson ratio stress and time dependencies, International Journal of Solids and Structures 35 (23) (1998) 3081 - 3095. doi: http: //dx.doi.org/10.1016/S0020-7683(97)00357-0

URL http://www.sciencedirect.com/science/article/pii/S0020768397003570

[24] J. D. Eshelby, The determination of the elastic field of an ellipsoidal inclusion, and related problems Proceedings of the Royal Society of London. Series A. Mathematical and Physical Sciences 241 (1226) (1957) 376-396. arXiv:http://rspa.royalsocietypublishing.org/content/241/1226/ 376.full.pdf+html, doi:10.1098/rspa.1957.0133

URL http://rspa.royalsocietypublishing.org/content/241/1226/376.abstract

[25] A. D. Drozdov, Chapter 2 - constitutive models in linear viscoelasticity, in: A. D. Drozdov (Ed.), Viscoelastic Structures, Academic Press, Burlington, 1998, pp. 25 - 106. doi:http://dx.doi.org/ 10.1016/B978-012222280-1/50002-3

URL http://www.sciencedirect.com/science/article/pii/B9780122222801500023

[26] Z. Hashin, S. Shtrikman, A variational approach to the theory of the elastic behaviour of multiphase materials, Journal of the Mechanics and Physics of Solids 11 (2) (1963) $127-140$. doi:10.1016/ 0022-5096(63)90060-7

URL http://www.sciencedirect.com/science/article/pii/0022509663900607

[27] W. L. Bond, The mathematics of the physical properties of crystals Bell System Technical Journal 22 (1) (1943) 1-72. doi:10.1002/j.1538-7305.1943.tb01304.x

URL http://dx.doi.org/10.1002/j.1538-7305.1943.tb01304.x

[28] B. Auld, Acoustic fields and waves in solids no. vol. 1 in Acoustic Fields and Waves in Solids, Wiley, 1973.

URL http://books .google.fr/books?id=9_wzAQAAIAAJ

[29] Z. Bažant, Numerical determination of long-range stress history from strain history in concrete Matériaux et Construction 5 (3) (1972) 135-141. doi:10.1007/BF02539255 URL http://dx.doi.org/10.1007/BF02539255

[30] C. Huet, Adaptation d'un algorithme de Bažant au calcul des multilames visco-élastiques vieillissants, Matériaux et Construction 13 (2) (1980) 91-98. doi:10.1007/BF02473805 URL http://dx.doi.org/10.1007/BF02473805

[31] Q. Nguyen, H. Di Benedetto, C. Sauzéat, Prediction of linear viscoelastic behaviour of asphalt mixes from binder properties and reversal, in: N. Kringos, B. Birgisson, D. Frost, L. Wang (Eds.), Multi-Scale Modeling and Characterization of Infrastructure Materials, Vol. 8 of RILEM Bookseries, Springer Netherlands, 2013, pp. 237-248. doi:10.1007/978-94-007-6878-9_17 URL http://dx.doi.org/10.1007/978-94-007-6878-9_17

[32] M. R. Islam, H. M. Faisal, R. A. Tarefder, Determining temperature and time dependent Poisson's ratio of asphalt concrete using indirect tension test Fuel 146 (0) (2015) 119 - 124. doi:http: //dx.doi.org/10.1016/j.fuel.2015.01.028 URL http://www.sciencedirect.com/science/article/pii/S0016236115000423

[33] E. Kassem, Z. Grasley, E. Masad, Viscoelastic Poisson's ratio of asphalt mixtures, International Journal of Geomechanics 13 (2) (2013) 162-169. arXiv:http://dx.doi.org/10.1061/(ASCE) GM. 1943-5622.0000199, doi:10.1061/(ASCE)GM.1943-5622.0000199 URL http://dx.doi.org/10.1061/(ASCE) GM.1943-5622.0000199

[34] A. Gudmarsson, N. Ryden, H. Di Benedetto, C. Sauzéat, N. Tapsoba, B. Birgisson, Comparing linear viscoelastic properties of asphalt concrete measured by laboratory seismic and tension-compression tests, Journal of Nondestructive Evaluation 33 (4) (2014) 571-582. doi:10.1007/ s10921-014-0253-9 URL http://dx.doi.org/10.1007/s10921-014-0253-9

[35] D. W. Christensen, D. A. Anderson, Interpretation of dynamic mechanical test data for paving grade asphalt cements, Journal of the Association of Asphalt Paving Technologists 61.

[36] N. I. M. Yusoff, G. D. Airey, M. R. Hainin, Predictability of complex modulus using rheological models Asian Journal of Scientific Research 3 (1) (2010) 18-30. doi:10.3923/ajsr.2010.18.30 
URL http://dx.doi.org/10.3923/ajsr.2010.18.30

[37] E. Behzadfar, S. G. Hatzikiriakos, Viscoelastic properties and constitutive modelling of bitumen Fuel 108 (0) (2013) 391 - 399. doi:http://dx.doi.org/10.1016/j.fuel.2012.12.035

URL http://www.sciencedirect.com/science/article/pii/S0016236112010599

[38] A. C. Collop, G. R. McDowell, Y. Lee, On the use of discrete element modelling to simulate the viscoelastic deformation behaviour of an idealized asphalt mixture, Geomechanics and Geoengineering 2 (2) (2007) 77-86. arXiv:http://dx.doi.org/10.1080/17486020701243128 doi: $10.1080 / 17486020701243128$ URL http://dx.doi.org/10.1080/17486020701243128

[39] X. yi Zhu, X. Wang, Y. Yu, Micromechanical creep models for asphalt-based multi-phase particlereinforced composites with viscoelastic imperfect interface International Journal of Engineering Science 76 (0) (2014) 34 - 46. doi:http://dx.doi.org/10.1016/j.ijengsci.2013.11.011 URL http://www.sciencedirect.com/science/article/pii/S0020722513001699

[40] F. Olard, H. Di Benedetto, General "2S2P1D" model and relation between the linear viscoelastic behaviours of bituminous binders and mixes Road Materials and Pavement Design 4 (2) (2003) 185224. arXiv:http://dx.doi.org/10.1080/14680629.2003.9689946 doi:10.1080/14680629.2003. 9689946.

URL http://dx.doi.org/10.1080/14680629.2003.9689946

[41] N. I. Md. Yusoff, D. Mounier, G. D. Airey, The 2S2P1D : An excellent liner viscoelastic model UNIMAS e-Journal of Civil Engineering 1 (2) (2010) 1-7. URL http://www.feng.unimas.my/ujce/images/article/Volume1Issue2April2010/7Vol1Issue2. pdf

[42] S. Alam, F. Hammoum, Viscoelastic properties of asphalt concrete using micromechanical selfconsistent model Archives of Civil and Mechanical Engineering 15 (1) (2015) 272 - 285. doi:http: //dx.doi.org/10.1016/j.acme.2014.02.005

URL http://www.sciencedirect.com/science/article/pii/S1644966514000429

[43] F. Olard, H. Di Benedetto, The "dbn" model: A thermo-visco-elasto-plastic approach for pavement behavior modeling, in: Journal of the Association of Asphalt Paving Technologists, Vol. 74, 2005, pp. 791-828.

[44] T. Mura, Isotropic inclusions, in: Micromechanics of defects in solids, Vol. 3 of Mechanics of Elastic and Inelastic Solids, Springer Netherlands, 1987, pp. 74-128. doi:10.1007/978-94-009-3489-4_2 URL http://dx.doi.org/10.1007/978-94-009-3489-4_2

[45] S. Torquato, Random Heterogeneous Materials: Microstructure and Macroscopic Properties Interdisciplinary Applied Mathematics, Springer, 2002. URL http://books.google.fr/books?id=PhG_X4-8DPAC

[46] O. Pierard, C. González, J. Segurado, J. LLorca, I. Doghri, Micromechanics of elasto-plastic materials reinforced with ellipsoidal inclusions International Journal of Solids and Structures 44 (21) (2007) 6945 - 6962. doi:http://dx.doi.org/10.1016/j.ijsolstr.2007.03.019 URL http://www .sciencedirect.com/science/article/pii/S0020768307001473

[47] F. de Larrard, Structures granulaires et formulation des bétons - Concrete Mixture - Proportionning - A scientific approach, no. 9, Modern technology Series, E \& FN SPON, Londres, 1999.

[48] K. Babu, D. Babu, Behaviour of lightweight expanded polystyrene concrete containing silica fume, Cement and Concrete Research 33 (5) (2003) 755 - 762. doi:http://dx.doi.org/10.1016/ S0008-8846(02) 01055-4

URL http://www.sciencedirect.com/science/article/pii/S0008884602010554

[49] R. L. Roy, E. Parant, C. Boulay, Taking into account the inclusions' size in lightweight concrete compressive strength prediction, Cement and Concrete Research 35 (4) (2005) 770 - 775 . doi: http://dx.doi.org/10.1016/j.cemconres.2004.06.002

URL http://www.sciencedirect.com/science/article/pii/S0008884604002480

[50] M. Bederina, L. Marmoret, K. Mezreb, M. Khenfer, A. Bali, M. Quéneudec, Effect of the addition of wood shavings on thermal conductivity of sand concretes: Experimental study and modelling Construction and Building Materials 21 (3) (2007) 662 - 668, fracture, Acoustic Emission and $\{\mathrm{NDE}\}$ in Concrete (KIFA-4). doi:http://dx.doi.org/10.1016/j.conbuildmat.2005.12.008 URL http://www.sciencedirect.com/science/article/pii/S0950061805003168

[51] H. M. Jennings, P. D. Tennis, Model for the developing microstructure in Portland cement pastes Journal of the American Ceramic Society 77 (12) (1994) 3161-3172. doi:10.1111/j.1151-2916. 1994.tb04565.x.

URL http://dx.doi.org/10.1111/j.1151-2916.1994.tb04565.x

[52] O. Bernard, F.-J. Ulm, E. Lemarchand, A multiscale micromechanics-hydration model for the early- 
age elastic properties of cement-based materials Cement and Concrete Research 33 (9) (2003) 1293 -1309. doi:http://dx.doi.org/10.1016/S0008-8846(03)00039-5

URL http://www.sciencedirect.com/science/article/pii/S0008884603000395

[53] D. P. Bentz, Three-dimensional computer simulation of Portland cement hydration and microstructure development, Journal of the American Ceramic Society 80 (1) (1997) 3-21. doi: 10.1111/j.1151-2916.1997.tb02785.x

URL http://dx.doi.org/10.1111/j.1151-2916.1997.tb02785.x

[54] D. Bentz, Modeling the influence of limestone filler on cement hydration using CEMHYD3D, Cement and Concrete Composites 28 (2) (2006) 124-129. doi:http://dx.doi.org/10.1016/j.cemconcomp. 2005.10.006

URL http://www.sciencedirect.com/science/article/pii/S0958946505001198

[55] C.-J. Haecker, E. Garboczi, J. Bullard, R. Bohn, Z. Sun, S. Shah, T. Voigt, Modeling the linear elastic properties of Portland cement paste Cement and Concrete Research 35 (10) (2005) 19481960. doi:http://dx.doi.org/10.1016/j.cemconres.2005.05.001

URL http://www.sciencedirect.com/science/article/pii/S0008884605001201

[56] H. N. Walker, D. S. Lane, P. E. Stutzman, Petrographic methods of examining hardened concrete: A petrographic manual, Tech. Rep. FHWA-HRT-04-150, Federal Highway Administration, Virginia Transportation Research Council (2006).

[57] Z. P. Bažant, S. Prasannan, Solidification theory for aging creep Cement and Concrete Research 18 (6) (1988) 923 - 932. doi:http://dx.doi.org/10.1016/0008-8846(88)90028-2 URL http://www.sciencedirect.com/science/article/pii/0008884688900282

[58] Z. P. Bažant, S. Baweja, Creep and shrinkage prediction model for analysis and design of concrete structures - model B3, Materials and Structures 28 (6) (1995) 357-365. doi:10.1007/BF02473152 URL http://dx.doi.org/10.1007/BF02473152

[59] L. Granger, Z. Bažant, Effect of composition on basic creep of concrete and cement paste, Journal of Engineering Mechanics 121 (11) (1995) 1261-1270. arXiv:http://dx.doi.org/10.1061/(ASCE) 0733-9399(1995) 121:11(1261), doi:10.1061/(ASCE) 0733-9399(1995) 121:11(1261). URL http://dx.doi.org/10.1061/(ASCE)0733-9399(1995) 121:11(1261)

[60] K. Velez, S. Maximilien, D. Damidot, G. Fantozzi, F. Sorrentino, Determination by nanoindentation of elastic modulus and hardness of pure constituents of Portland cement clinker Cement and Concrete Research 31 (4) (2001) 555 - 561. doi:http://dx.doi.org/10.1016/S0008-8846(00) 00505-6

URL http://www.sciencedirect.com/science/article/pii/S0008884600005056

[61] G. Constantinides, F.-J. Ulm, The effect of two types of C-S-H on the elasticity of cement-based materials: Results from nanoindentation and micromechanical modeling, Cement and Concrete Research 34 (1) (2004) 67 - 80. doi:http://dx.doi.org/10.1016/S0008-8846(03)00230-8 URL http://www.sciencedirect.com/science/article/pii/S0008884603002308

[62] L. Sorelli, G. Constantinides, F.-J. Ulm, F. Toutlemonde, The nano-mechanical signature of ultra high performance concrete by statistical nanoindentation techniques Cement and Concrete Research 38 (12) (2008) 1447 - 1456. doi:http://dx.doi.org/10.1016/j.cemconres.2008.09.002 URL http://www.sciencedirect.com/science/article/pii/S0008884608001567

[63] M. Shahidi, B. Pichler, C. Hellmich, Viscous interfaces as source for material creep: A continuum micromechanics approach European Journal of Mechanics - A/Solids 45 (2014) 41 - 58. doi: http: //dx.doi.org/10.1016/j.euromechsol.2013.11.001

URL http://www.sciencedirect.com/science/article/pii/S0997753813001368

[64] M. Shahidi, B. Pichler, C. Hellmich, Interfacial micromechanics assessment of classical rheological models. i: Single interface size and viscosity, Journal of Engineering Mechanics 0 (0) (2015) 04015092. arXiv:http://dx.doi.org/10.1061/(ASCE)EM.1943-7889.0001012 doi:10. 1061/(ASCE) EM.1943-7889.0001012

URL http://dx.doi.org/10.1061/(ASCE)EM.1943-7889.0001012

[65] M. Shahidi, B. Pichler, C. Hellmich, Interfacial micromechanics assessment of classical rheological models. ii: Multiple interface sizes and viscosities Journal of Engineering Mechanics 0 (0) (2015) 04015093. arXiv:http://dx.doi.org/10.1061/(ASCE) EM.1943-7889.0001013 doi: 10.1061/(ASCE) EM.1943-7889.0001013 URL http://dx.doi.org/10.1061/(ASCE) EM.1943-7889.0001013

[66] L. Granger, Comportement différé du béton dans les enceintes de centrales nucléaires : analyse et modélisation, Ph.D. thesis, Ecole Nationale des Ponts et Chaussées (1995).

[67] J. Edgington, D. Hannant, Steel fibre reinforced concrete. the effect on fibre orientation of compaction by vibration. Matériaux et Construction 5 (1) (1972) 41-44. doi:10.1007/BF02479076 
URL http://dx.doi.org/10.1007/BF02479076

[68] M. Rudzki, M. Bugdol, T. Ponikiewski, An image processing approach to determination of steel fibers orientation in reinforced concrete, in: E. Pietka, J. Kawa (Eds.), Information Technologies in Biomedicine, Vol. 7339 of Lecture Notes in Computer Science, Springer Berlin Heidelberg, 2012, pp. 143-150. doi:10.1007/978-3-642-31196-3_15

URL http://dx.doi.org/10.1007/978-3-642-31196-3_15

[69] N. Sebaibi, M. Benzerzour, N. E. Abriak, Influence of the distribution and orientation of fibres in a reinforced concrete with waste fibres and powders Construction and Building Materials 65 (0) (2014) $254-263$. doi:http://dx.doi.org/10.1016/j.conbuildmat.2014.04.134

URL http://www.sciencedirect.com/science/article/pii/S095006181400467X

[70] J. Sanahuja, L. Dormieux, G. Chanvillard, Modelling elasticity of a hydrating cement paste, Cement and Concrete Research 37 (10) (2007) 1427 -1439. doi :http://dx.doi.org/10.1016/j.cemconres. 2007.07 .003

URL http://www.sciencedirect.com/science/article/pii/S0008884607001548

[71] K. L. Scrivener, A. K. Crumbie, P. Laugesen, The interfacial transition zone (ITZ) between cement paste and aggregate in concrete Interface Science 12 (2004) 411-421, 10.1023/B:INTS.0000042339.92990.4c.

URL http://dx.doi.org/10.1023/B:INTS.0000042339.92990.4c

[72] C. Neubauer, H. Jennings, E. Garboczi, A three-phase model of the elastic and shrinkage properties of mortar. Advanced Cement Based Materials 4 (1) (1996) 6-20. doi:http://dx.doi.org/10. 1016/S1065-7355(96) 90058-9.

URL http://www.sciencedirect.com/science/article/pii/S1065735596900589

[73] J. Nadeau, A multiscale model for effective moduli of concrete incorporating ITZ water-cement ratio gradients, aggregate size distributions, and entrapped voids Cement and Concrete Research 33 (1) (2003) 103 - 113. doi:http://dx.doi.org/10.1016/S0008-8846(02)00931-6 URL http://www.sciencedirect.com/science/article/pii/S0008884602009316

[74] E. Garboczi, J. Berryman, Elastic moduli of a material containing composite inclusions: effective medium theory and finite element computations Mechanics of Materials 33 (8) (2001) $455-470$. doi:http://dx.doi.org/10.1016/S0167-6636(01)00067-9

URL http://www.sciencedirect.com/science/article/pii/S0167663601000679

[75] E. Gal, R. Kryvoruk, Meso-scale analysis of FRC using a two-step homogenization approach Computers \& Structures 89 (11-12) (2011) 921-929, computational Fluid and Solid Mechanics 2011 Proceedings Sixth MIT Conference on Computational Fluid and Solid Mechanics. doi:http: //dx.doi.org/10.1016/j.compstruc.2011.02.006

URL http://www.sciencedirect.com/science/article/pii/S0045794911000393

[76] F. Grondin, M. Matallah, How to consider the interfacial transition zones in the finite element modelling of concrete?, Cement and Concrete Research 58 (0) (2014) $67-75$. doi:http://dx.doi. org $/ 10.1016 / j$.cemconres.2014.01.009

URL http://www.sciencedirect.com/science/article/pii/S0008884614000106

[77] J. Sanahuja, Efficient Homogenization of Ageing Creep of Random Media: Application to Solidifying Cementitious Materials, 2013, Ch. 23, pp. 201-210. arXiv:http://ascelibrary.org/doi/pdf/10. 1061/9780784413111.023, doi:10.1061/9780784413111.023

URL http://ascelibrary.org/doi/abs/10.1061/9780784413111.023

[78] D. S. Atrushi, Tensile and compressive creep of early age concrete: Testing and modelling, Ph.D. thesis, The Norwegian University of Science and Technology Trondheim, Norway (2003).

[79] S. Ullah, B. Pichler, S. Scheiner, C. Hellmich, Influence of shotcrete composition on load-level estimation in natm-tunnel shells: Micromechanics-based sensitivity analyses International Journal for Numerical and Analytical Methods in Geomechanics 36 (9) (2012) 1151-1180. doi:10.1002/ nag.1043

URL http://dx.doi.org/10.1002/nag.1043

[80] M. Rendek, A. Lion, Amplitude dependence of filler-reinforced rubber: Experiments, constitutive modelling and FEM - implementation International Journal of Solids and Structures 47 (21) (2010) 2918 - 2936. doi:http://dx.doi.org/10.1016/j.ijsolstr.2010.06.021 URL http://www.sciencedirect.com/science/article/pii/S0020768310002428

[81] F. Fritzen, T. Böhlke, Reduced basis homogenization of viscoelastic composites Composites Science and Technology 76 (0) (2013) 84 -91. doi:http://dx.doi.org/10.1016/j.compscitech.2012.12. 012

URL http://www.sciencedirect.com/science/article/pii/S0266353812004198

[82] L. J. Siefken, E. W. Coryell, E. A. Harvego, Scdap/relap5/mod3.3 code manual matpro a library of 
materials properties for light-water-accident analysis, Tech. rep., Idaho National Engineering and Environmental Laboratory (january 2001).

[83] R. Largenton, J.-C. Michel, P. Suquet, Extension of the nonuniform transformation field analysis to linear viscoelastic composites in the presence of aging and swelling Mechanics of Materials $73(0)$ (2014) 76 - 100. doi:http://dx.doi.org/10.1016/j.mechmat.2014.02.004

URL http://www.sciencedirect.com/science/article/pii/S0167663614000325

[84] A. Aili, M. Vandamme, J.-M. Torrenti, B. Masson, Theoretical and practical differences between creep and relaxation poisson's ratios in linear viscoelasticity Mechanics of Time-Dependent Materials 19 (4) (2015) 537-555. doi:10.1007/s11043-015-9277-5

URL http://dx.doi.org/10.1007/s11043-015-9277-5

[85] J. Beaudoin, Comparison of mechanical properties of compacted calcium hydroxide and Portland cement paste systems, Cement and Concrete Research 13 (3) (1983) $319-324$. doi:http://dx. doi.org/10.1016/0008-8846(83) 90030-3

URL http://www.sciencedirect.com/science/article/pii/0008884683900303

[86] F. Wittmann, Estimation of the modulus of elasticity of calcium hydroxide Cement and Concrete Research 16 (6) (1986) 971 - 972. doi:http://dx.doi.org/10.1016/0008-8846(86)90021-9 URL http://www.sciencedirect.com/science/article/pii/0008884686900219

[87] P. J. Monteiro, C. Chang, The elastic moduli of calcium hydroxide, Cement and Concrete Research 25 (8) (1995) 1605 - 1609. doi:http://dx.doi.org/10.1016/0008-8846(95)00154-9

URL http://www.sciencedirect.com/science/article/pii/0008884695001549

[88] S. Kamali, M. Moranville, E. Garboczi, S. Prené, B. Gérard, Hydrate dissolution influence on the Young's modulus of cement paste, in: Fracture Mechanics of Concrete Structures (FraMCoS-V), 2004, pp. 631-638.

URL http://framcos.org/FraMCoS-5/kamali.hydrate.pdf

[89] V. Šmilauer, Z. Bittnar, Microstructure-based micromechanical prediction of elastic properties in hydrating cement paste, Cement and Concrete Research 36 (9) (2006) 1708 - 1718. doi:http: //dx.doi.org/10.1016/j.cemconres.2006.05.014.

URL http://www.sciencedirect.com/science/article/pii/S0008884606001499 